\title{
Marriage and motherhood: An exploratory study of the social and reproductive health status of married young women in Gujarat and West Bengal
}

F. Ram

Ranjana Sinha

S.K. Mohanty

Arup Das

Aruna Lakhani

See next page for additional authors

Follow this and additional works at: https://knowledgecommons.popcouncil.org/departments_sbsr-pgy

Part of the Demography, Population, and Ecology Commons, Family, Life Course, and Society

Commons, Gender and Sexuality Commons, and the International Public Health Commons

How does access to this work benefit you? Let us know!

\section{Recommended Citation}

Ram, F., Ranjana Sinha, S.K. Mohanty, Arup Das, Aruna Lakhani, Nicole Haberland, and K.G. Santhya. 2006. "Marriage and motherhood: An exploratory study of the social and reproductive health status of married young women in Gujarat and West Bengal." New Delhi: Population Council. 


\section{Authors}

F. Ram, Ranjana Sinha, S.K. Mohanty, Arup Das, Aruna Lakhani, Nicole Haberland, and K.G. Santhya 
This report is the result of a collaborative study between International Institute for Population Sciences, Mumbai and the Population Council, as part of an intervention project focused on married young women implemented in Gujarat by Deepak Charitable Trust, Vadodara and in West Bengal by Child In Need Institute, Kolkata, in partnership with the Population Council.

\section{For additional copies of this report, please contact:}

Population Council

Zone 5A, Ground Floor

India Habitat Centre

Lodi Road

New Delhi 110003

Phone:011-2464 2901/02 email: info-india@popcouncil.org

International Institute for Population Sciences (IIPS) is a teaching and research institute that offers academic courses in population sciences. IIPS has been actively involved in building the capacity of Population Research Centres, and other state and central government offices addressing demographic issues in the country. It has a proven record in conducting national-and sub-national-level studies in reproductive health, including the National Family Health Surveys.

Child In Need Institute (CINI), a non-governmental organisation established in 1974 in West Bengal, aims to achieve sustainable health and nutrition development for women and children. CINI's activities focus on areas such as safe motherhood and child survival, nutritional services for vulnerable groups, reproductive health services for adolescents, male involvement in reproductive health, and gender relations and women's empowerment.

Deepak Charitable Trust (DCT), a non-governmental organisation established in 1981 in Gujarat, strives to improve the quality of life of women through developmental activities and interventions. Its main focus has been in areas such as reproductive and sexual health education, livelihoods and women's empowerment. DCT reaches out to people across 50 villages in Vadodara and Surendranagar districts in Gujarat and Raigarh district in Maharashtra.

The Population Council is an international, non-profit, non-governmental organisation that seeks to improve the well-being and reproductive health of current and future generations around the world and to help achieve a humane, equitable and sustainable balance between people and resources. The Council conducts biomedical, social science and public health research, and helps build research capacities in developing countries.

\section{Copyright@ 2006 Population Council}

Suggested citation: Ram, F., R.K. Sinha, S.K. Mohanty et al. 2006. Marriage and Motherhood: An Exploratory Study of the Social and Reproductive Health Status of Married Young women in Gujarat and West Bengal, India. New Delhi: Population Council. 


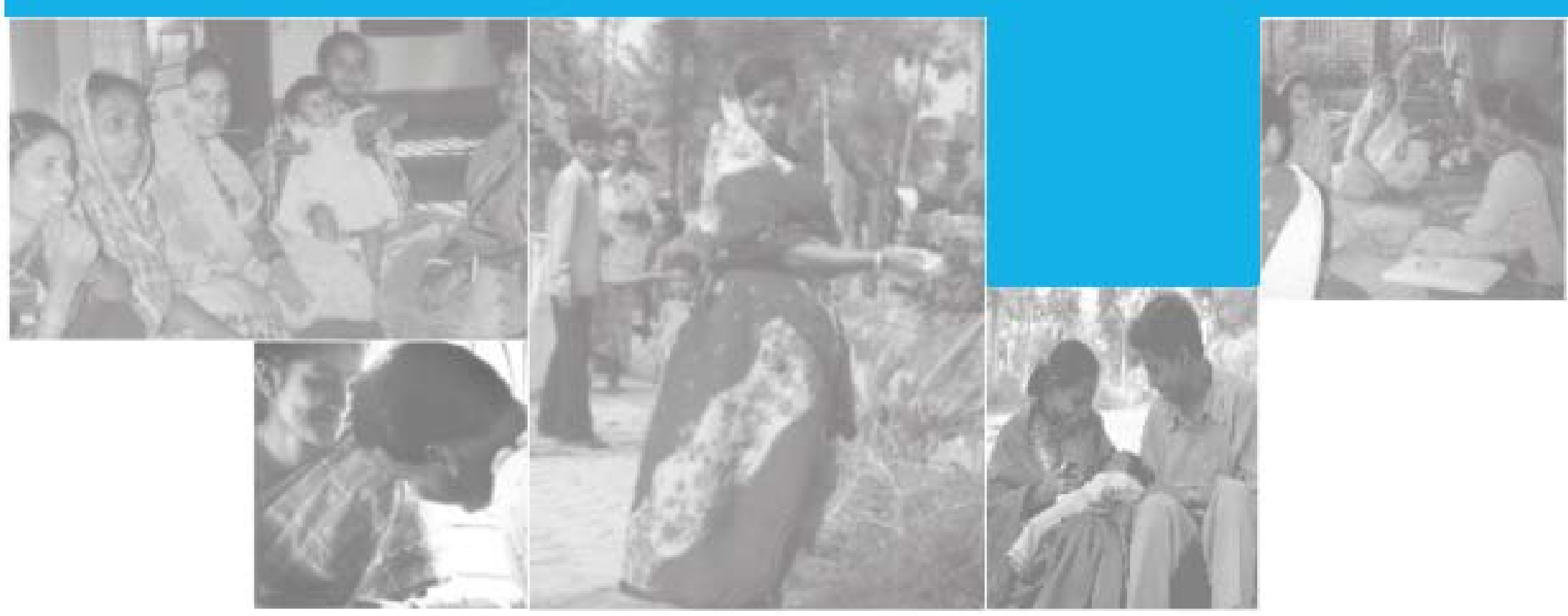

\title{
Marriage and Motherhood:
}

An exploratory study of the social and reproductive health status of married young women in Gujarat and West Bengal, India

\author{
F. Ram \\ R.K. Sinha \\ S.K. Mohanty \\ International Institute for Population Sciences
}

Arup Das

Child In Need Institute

Aruna Lakhani

Deepak Charitable Trust

Nicole Haberland

K.G. Santhya

Population Council 


\section{Contents}

Acknowledgements

List of tables and figures vi

Abstract viii

Chapter 1: Introduction

Study setting

Response rate 4

Chapter 2: Characteristics of respondents 5

Chapter 3: Livelihoods, decision-making, mobility and social networks 7

$\begin{array}{ll}\text { Work participation } & 7\end{array}$

Persons influencing decisions regarding married young women's work participation 8

Management of earnings 8

Savings practice $\quad 9$

$\begin{array}{ll}\text { Household-related decision-making } & 10\end{array}$

$\begin{array}{lr}\text { Mobility } & 10\end{array}$

Exposure to mass media 11

$\begin{array}{lr}\text { Social networks } & 11\end{array}$

Chapter 4: Gender role attitudes, and perceptions and experience of domestic violence 14

\begin{tabular}{ll}
\hline Gender role attitudes & 14
\end{tabular}

Perceptions and experience of domestic violence 15

\begin{tabular}{ll} 
Chapter 5: & The marriage process \\
\hline
\end{tabular}

\begin{tabular}{lr}
\hline Transition to marriage & 17
\end{tabular}

Negotiations over and payment of dowry 19

Moving into the marital home $\quad 19$

$\begin{array}{lr}\text { Transition to sexual life } & 20\end{array}$

Relationship with spouse $\quad 22$

Chapter 6: Awareness and knowledge of reproductive health 24

\begin{tabular}{ll}
\hline Knowledge of contraceptive methods & 24
\end{tabular}

Knowledge of the fertile period and determinant of the sex of the baby 25

Knowledge of danger signs during pregnancy, delivery, the postpartum period 25

and in newborns

Knowledge of breastfeeding practices $\quad 25$

Knowledge of sexually transmitted infections and HIV/AIDS 26

$\begin{array}{ll}\text { Interaction with health workers } & 28\end{array}$ 
Chapter 7: Reproductive and sexual health decision-making and practices

Contraceptive dynamics

Timing of first pregnancy $\quad 31$

Preferred timing of first pregnancy 31

Spousal and non-spousal discussion and decision-making about timing of first pregnancy 32

Actual timing of first pregnancy 33

Pregnancy experience $\quad 33$

Diet, work and sexual behaviour 34

Antenatal check-up 34

Delivery experience $\quad 35$

Postpartum experience $\quad 36$

Breastfeeding practices and immunisation of the baby 37

Self-reported complications/problems during pregnancy, delivery, the postpartum period 38

and in newborns

Beyond the first birth: Desired family size and spacing the second birth 39

Chapter 8: Support during pregnancy, delivery and the postpartum period 41

$\begin{array}{ll}\text { Support during pregnancy } & 41\end{array}$

Harassment during pregnancy $\quad 41$

Support during delivery $\quad 42$

Support during the postpartum period $\quad 43$

Harassment during the postpartum period $\quad 43$

Chapter 9: Summary and conclusion $\quad 44$

Married young women's social isolation and limited autonomy 44

Gender role attitudes and experience of physical abuse 45

The marital experience: Transition, intimacy and sexual initiation $\quad 45$

Knowledge of reproductive health $\quad 46$

Reproductive health practices $\quad 46$

Spousal communication and decision-making on reproductive health matters 47

$\begin{array}{ll}\text { Support for the first birth } & 47\end{array}$

$\begin{array}{ll}\text { Conclusion } & 48\end{array}$

$\begin{array}{ll}\text { References } & 49\end{array}$

\begin{tabular}{lr} 
Appendix 1 & 50 \\
\hline
\end{tabular}

$\begin{array}{lr}\text { Authors } & 51\end{array}$ 


\section{Acknowledgements}

This study has benefited immeasurably from the input of many. At the outset, we are enormously grateful for the partnership and support of the Department for International Development (DFID), the Bill \& Melinda Gates Foundation, the Hewlett Foundation, the John D. and Catherine T. MacArthur Foundation, the Andrew W. Mellon Foundation, and the Summit Foundation/ the National Foundation for the National Capital Region for making this study possible.

We would like to thank the young women in Diamond Harbour and Vadodara who generously gave us their time and shared their life experiences. We would also like to thank the investigators and other members of the field team who painstakingly collected the data-often in trying circumstancesas well as the research officers who ably supervised the data collection and analysis.

Our technical advisory group-Halida Hanum Akhter, Shireen Jejeebhoy, Michael Koenig, Janet Molzan Turan - provided invaluable advice in developing the study design and intervention plans. A special thanks goes to Judith Bruce, Saroj Pachauri, Shireen Jejeebhoy and Beverly Winikoff for their collegial support, mentoring and guidance throughout the study. We are grateful to Elizabeth McGrory, part of our team up through the finalization of the questionnaire design, for her clear and critical thinking. We would also like to thank Annabel Erulkar and Barbara Mensch for reviewing an earlier draft of this report and providing helpful comments. We are grateful to Deepika Ganju for her editorial

contribution and careful attention to detail. Finally, we are hugely indebted to Asha Matta for her help in designing the report and Vijaya Nidadavolu for overseeing production of this report. 


\section{List of tables and figures}

Table 1.1 Profile of study districts and states 2

Table $1.2 \quad$ Coverage of the study and response rate 4

Table 2.1 Profile of respondents $\quad 6$

$\begin{array}{lll}\text { Table } 3.1 & \text { Work participation } & 7\end{array}$

Table $3.2 \quad$ Connections with natal home, non-familial peers and community 13

$\begin{array}{lll}\text { Table } 4.1 & \text { Gender role attitudes } & 14\end{array}$

$\begin{array}{lll}\text { Table } 5.1 & \text { Initial feelings on moving into the marital home } & 19\end{array}$

$\begin{array}{lll}\text { Table } 5.2 & \text { Feelings before and after first sexual intercourse } & 21\end{array}$

$\begin{array}{lll}\text { Table } 6.1 & \text { Perceptions of methods to prevent sexually transmitted infections } & 27\end{array}$

Table $6.2 \quad$ Knowledge of ways of preventing HIV/AIDS 28

Table $6.3 \quad$ Percentage of married young women who received information 29

Table 7.1 Married young women's and their husbands' preferences regarding 31

the timing of first pregnancy

Table 7.2 Reasons for wanting to delay the first pregnancy 32

Table 7.3 Percentage of married young women who received antenatal check-ups 34

Table 7.4 Arrangements for delivery 35

Table 7.5 Duration of postpartum isolation 36

$\begin{array}{lll}\text { Table 7.6 } & \text { Percentage of married young women who received postpartum check-ups } & 37\end{array}$

Table 7.7 Time of initiating breastfeeding and the practice of feeding colostrum 38

Table $7.8 \quad$ Desired family size 39

Table 7.9 Preferences regarding interval between first and second birth 40

Table 8.1 Person who harassed married young women during pregnancy 42 
$\begin{array}{lll}\text { Figure } 3.1 & \text { Persons influencing decisions regarding work participation } & 8\end{array}$

$\begin{array}{lll}\text { Figure } 3.2 & \text { Management of earnings } & 9\end{array}$

Figure $3.3 \quad$ Place of savings 9

$\begin{array}{lll}\text { Figure } 3.4 & \text { Persons influencing household-related decisions } & 10\end{array}$

Figure 3.5 Percentage of young married women who could go unescorted to 11

Figure 3.6 Regular exposure to mass media 12

$\begin{array}{lll}\text { Figure 4.1 Married young women reporting egalitarian gender attitudes by age group } & 15\end{array}$

Figure 4.2 Married young women who agreed with reasons for wife-beating 15

$\begin{array}{lll}\text { Figure 5.1 } & \text { Percentage of 20-24 year old women married by exact ages } & 17\end{array}$

$\begin{array}{lll}\text { Figure 5.2 Spousal age difference } & 18\end{array}$

$\begin{array}{lll}\text { Figure 5.3 Familiarity with husband at the time of marriage } & 18\end{array}$

$\begin{array}{lll}\text { Figure } 5.4 & \text { Initial source of information on sex } & 20\end{array}$

Figure 5.5 Frequency of spending time together with husband 22

Figure 5.6 Frequency of husbands' support of young married women in the event 23

Figure 6.1 Awareness and knowledge of selected contraceptive methods $\quad 24$

Figure 6.2 Awareness of complications during pregnancy, delivery, the postpartum 25 period and in newborns

$\begin{array}{lll}\text { Figure } 6.3 & \text { Knowledge of breastfeeding practices } & 26\end{array}$

$\begin{array}{lll}\text { Figure } 6.4 & \text { Knowledge of sexually transmitted infections } & 26\end{array}$

$\begin{array}{lll}\text { Figure 7.1 } & \text { Ever use of contraceptive methods } & 30\end{array}$

$\begin{array}{lll}\text { Figure 7.2 } & \text { Persons influencing decisions regarding contraceptive use } & 31\end{array}$

Figure 7.3 Persons influencing decisions regarding timing of first pregnancy 32

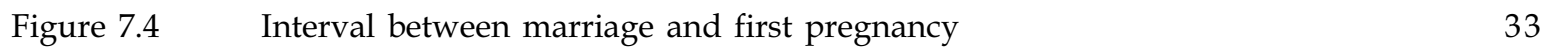

Figure 7.5 Percentage of married young women who delivered at a health facility 36

Figure 7.6 Self-reported problems/ complications during pregnancy, delivery, the 38

Figure 7.7 Persons influencing decisions regarding spacing the second birth 40

$\begin{array}{lll}\text { Figure } 8.1 & \text { Type of support received during pregnancy } & 41\end{array}$

$\begin{array}{lll}\text { Figure } 8.2 & \text { Type of support received during delivery } & 42\end{array}$ 


\section{Abstract}

In India, sexual activity and childbearing among young women take place overwhelmingly within the context of marriage. Despite the high prevalence of early marriage, little is known about the lives of married young women including the nature of the early years of marriage or the pressures that they face, and few interventions have focused on supporting this group. In response, the Population Council, in partnership with Child In Need Institute in Kolkata (West Bengal) and Deepak Charitable Trust in Vadodara (Gujarat), initiated the First-Time Parents project. This project aimed to develop and test an integrated package of health and social interventions that would improve married young women's reproductive and sexual health knowledge and practices, and expand their ability to act in their own interests.

As part of a quasi-experimental study to test the effects of the project, International Institute for Population Sciences (IIPS) and the Population Council conducted a baseline survey in selected rural sites from late 2002 to early 2003. All women meeting the selection criteria-i.e. newly-married, firsttime pregnant or first-time mothers, regardless of age-in the intervention and control villages were invited to be interviewed. A total of 1,079 and 1,036 married young women were interviewed in Vadodara, Gujarat and in Diamond Harbour, West Bengal, respectively. This report presents findings from the baseline survey.

Data on married young women's social situation present a picture of considerable isolation and limited autonomy. Few women for example, reported having friends outside their families, or being members or beneficiaries of NGO or government services and programmes. Most women were not involved in household decision-making, and the vast majority had highly circumscribed mobility. The majority described the experience of moving to the marital home as lonely and frightening. Sexual initiation was almost always with their husbands and within marriage, and most women in both sites reported that they felt frightened before having sexual intercourse for the first time.

The study also examined married young women's knowledge, participation in decision-making and practices related to reproductive health, and the support received over the course of their first birth. Women were generally aware of contraceptive methods and of some of the signs of complications that a woman might experience during pregnancy, delivery and the postpartum period. However, awareness of many other reproductive health topics, for example prevention of sexually transmitted infections/ HIV, was poor. Decisions regarding contraceptive use, timing of first birth and other reproductive health matters were often made jointly, especially with their husbands. However, among a substantial 
proportion of women, husbands or other family members made such decisions independently, without the young woman's input. While findings on antenatal check-ups and delivery preparations were somewhat encouraging, other aspects of maternity-related care, for example postpartum check-ups and breastfeeding, were not as positive. During the first pregnancy, delivery and the postpartum period, women generally received fairly significant physical and emotional support from their husbands, mothers and mothers-in-law.

In brief, while married young women were clearly imbedded in a social order that isolated and silenced them, many women also found support from their husbands. And while many women were frightened and lonely as they entered their marital home and sexual life, many came to feel comfortable in their new home and enjoyed intimate relations with their husbands. Data also suggest considerable misinformation and gaps in care and prevention. Significant steps should be taken to relay accurate information on reproduction and the prevention of infection, to help young couples achieve their reproductive intentions, and to provide critical postpartum and neonatal guidance and care. Augmenting and redirecting services and outreach to this population are unlikely to be adequate; it is also critical to directly address and ameliorate their social disadvantage and isolation as well as to engage gatekeepers such as husbands, mothers-in-law and mothers. 


\section{CHAPTER 1}

\section{Introduction}

In India, sexual activity and childbearing among young women take place overwhelmingly within the context of marriage. While age at marriage for girls is increasing in India, as elsewhere in the developing world, early marriage continues to be a significant practice. As many as 34 percent of adolescent girls aged 15-19 are already married, presumably sexually active, and under pressure to bear a first child, while fewer than 10 percent of unmarried girls are reported to be sexually experienced (IIPS and ORC Macro, 2000; Jejeebhoy, 2000).

Although sexual activity occurs within the socially sanctioned institution of marriage, marriage does not inherently make sex safe, voluntary or pleasurable. Nor does the fact that the birth is often desired, expected by the community or within the marital boundary, make childbearing safe for a young first-time mother. Indeed, first-time mothers below age 16 are more vulnerable to prolonged or obstructed labour and fistula than older, parous females (Lloyd et al., 2005; Miller and Lester, 2003). In some contexts, due to frequent sexual activity, low likelihood of condom use and large spousal age differences, girls married before the age of 18 may face significant risks of acquiring HIV (Bruce and Clark, 2003). And while research on sexual coercion within marriage is limited, Santhya and Jejeebhoy (2006) document several studies in India indicating that young women's early sexual encounters within marriage are often described as frightening and non-consensual.

Despite the high prevalence of early marriage, little is known about the lives of married young women including the nature of the early years of marriage or the pressures they face, and little has been done to support them. In view of this, the Population Council, in partnership with Child In Need Institute in Kolkata and Deepak Charitable Trust in Vadodara, initiated an intervention project, the First-Time Parents project. This project aimed to develop and test an integrated package of health and social interventions that would improve married young women's reproductive and sexual health knowledge and practices, and expand their ability to act in their own interests. In this report, married adolescent girls are also included within the category of married young women.

The situation of married young women described in this report is from the baseline survey in the project sites in Vadodara and Diamond Harbour conducted by International Institute for Population Sciences (IIPS) and the Population Council. These findings fill a significant gap in existing research by providing information on the situation and needs of newly-married and firsttime pregnant/postpartum young women in India. 


\section{Study objectives}

The objectives of the baseline survey were to:

- examine married young women's knowledge of key reproductive health issues;

- understand their reproductive health behaviours and practices;

- $\quad$ assess partner communication and support among married young women; and

- $\quad$ assess social networking and agency among these women.

\section{Study setting}

The survey was conducted in two rural settings in India -- Vadodara Block in Vadodara district, Gujarat, and Diamond Harbour Block in South 24 Pargana district, West Bengal. A few key indicators of the study districts, and the states in which they are located, are shown in Table 1.1.

\section{Study design}

A cross-sectional survey of all married young women meeting the eligibility criteria, regardless of age, was conducted in 24 villages, with a population of about 46,000 in Vadodara Block, Gujarat, and 25 villages, with a population of 42,000 in Diamond Harbour Block, West Bengal. The two blocks were purposively selected to cover villages where Deepak Charitable Trust and Child In Need Institute were planning to implement the First-Time Parents project, and villages that would serve as controls in an evaluation of the project.

Respondents included young women who were newly-married, first-time pregnant or firsttime mothers, regardless of age. Newly-married women were defined as those who had been married for two years or less at the time of the survey; first-time pregnant women were those who had not previously had a live birth but were pregnant at the time of the survey; and first-time

Table 1.1

Profile of study districts and states

\begin{tabular}{|c|c|c|c|c|}
\hline Characteristics & $\begin{array}{l}\text { Vadodara } \\
\text { District, } \\
\text { Gujarat }\end{array}$ & Gujarat State & $\begin{array}{c}\text { South } 24 \\
\text { Pargana District, } \\
\text { West Bengal }\end{array}$ & $\begin{array}{c}\text { West Bengal } \\
\text { State }\end{array}$ \\
\hline Population $^{1}$ & $3,639,775$ & $50,596,992$ & $6,909,015$ & $80,221,171$ \\
\hline Overall sex ratio ${ }^{1, *}$ & 919 & 921 & 938 & 934 \\
\hline Child sex ratio (0-6 years) ${ }^{1, *}$ & 875 & 878 & 969 & 963 \\
\hline Male literacy $(\%)^{1}$ & 80.7 & 80.5 & 79.9 & 77.6 \\
\hline Female literacy $(\%)^{1}$ & 61.3 & 58.6 & 59.7 & 60.2 \\
\hline Current contraceptive use $(\%)^{2}$ & 58.9 & 58.4 & 67.3 & 68.9 \\
\hline Full antenatal care $(\%)^{2, * *}$ & 31.3 & 42.7 & 30.1 & 33.4 \\
\hline Institutional delivery $(\%)^{2}$ & 39.1 & 46.1 & 29.8 & 38.9 \\
\hline
\end{tabular}

* Sex ratio: number of females per 1,000 males.

** Full antenatal care includes at least 3 antenatal check-ups, iron and folic supplements and at least 1 tetanus-toxoid injection.

Sources: ${ }^{1}$ Registrar General of India, 2001; ${ }^{2}$ International Institute for Population Sciences, 2001 
mothers included those who had a first live birth and were within 18 months postpartum at the time of the survey. Respondents were identified through a rapid household listing in the study area, and all eligible women were invited to participate in the survey.

\section{Data collection}

To identify eligible women for the survey, a listing of all the households was undertaken in August-October 2002 in the study villages. All members of a household and any visitors staying in the household the night before the interview were listed. For each listed person, information was collected on age, sex, relationship to the head of the household, marital status, year and month of marriage, whether they had ever given birth and the number of births.

A structured questionnaire was jointly developed by International Institute for Population Sciences (IIPS) and the Population Council. The questionnaire was translated into the respective local languages and then backtranslated. Draft questionnaires were pilot tested with 50 eligible women in two villages that were not part of the study (one each in Vadodara and Diamond Harbour), and necessary modifications made.
Investigators and supervisors were recruited locally. Training workshops were held for one week for investigators involved in conducting the baseline survey. The collection of baseline data started in September/October 2002, and was completed by early February 2003. To ensure the quality of data collection, field supervisors regularly supervised and monitored the fieldwork, field-edited the completed questionnaires, carried out spot-checks of interviews, and helped investigators as required. Additionally, the research team, comprised of IIPS faculty and research officers, regularly monitored the collection of data. Data processing for both the household listing and baseline survey was carried out at IIPS. Consistency checks were carried out, and the data cleaned and processed to generate tables.

Several unforeseen problems were encountered in the data collection process. The non-availability of listed respondents due to the frequent (customary) movement of young women between their natal and marital homes delayed the pace of the data collection and reduced the coverage in both sites more than anticipated. Also, the quick transition of respondents, for instance from a first-time mother to second-time mother, reduced the number of eligible women initially identified at the time of the household listing. 


\section{Response rate}

Refusal rates were low; however, as noted above, some women were no longer eligible due to a second live birth or the dissolution of marriage (i.e. separation or widowhood). In Vadodara, 1,711 eligible women were identified during the household listing, of whom 1,538 were eligible at the time of the baseline survey (Table 1.2).
After at least four rounds of visits by the field team, 1,079 respondents (70 percent of the women identified) were successfully interviewed. In Diamond Harbour, 1,395 eligible women were identified during the household listing, of whom 1,324 were eligible at baseline, and 1,036 respondents (78 percent of the women identified) were successfully interviewed.

Table 1.2

Coverage of the study and response rate

\begin{tabular}{|c|c|c|}
\hline & Vadodara & Diamond Harbour \\
\hline Number of households listed & 8,838 & 8,130 \\
\hline Total population listed & 45,679 & 42,319 \\
\hline Usual resident $(\%)$ & 96.3 & 98.7 \\
\hline Visitors(\%) & 3.7 & 1.3 \\
\hline Number of eligible women identified during listing & 1,711 & 1,395 \\
\hline Number of women eligible at baseline survey* & 1,538 & 1,324 \\
\hline Successfully interviewed & 1,079 & 1,036 \\
\hline Partially interviewed & 19 & 5 \\
\hline Refused & 14 & 3 \\
\hline Not at Home & 426 & 280 \\
\hline Response rate (\% of women eligible) & 70 & 78 \\
\hline
\end{tabular}

*Includes all women identified as eligible, minus those whose status changed between the household listing and baseline survey and no longer met the eligibility criteria at the time of the baseline survey. 


\section{CHAPTER 2}

\section{Characteristics of respondents}

The socio-demographic characteristics of the respondents, summarised in Table 2.1, show some similarities and some differences between the two study sites. In both sites, the majority of respondents were adolescents (i.e. aged less than 20), and husbands were typically older than their wives. However, husbands tended to be younger in Vadodara than in Diamond Harbour. While the vast majority of respondents in both sites had completed some years of schooling, many had discontinued schooling after primary school.
In Vadodara, respondents were predominantly Hindu (99 percent); in Diamond Harbour, 55 percent of respondents were Muslim. The vast majority of young women resided in rural areas before marriage. Nine percent of married young women in Vadodara, compared to 30 percent in Diamond Harbour, were living in nuclear families. In Vadodara, only a small proportion of respondents (11 percent) lived in households with a low standard of living index, compared to 44 percent of respondents in Diamond Harbour (see Appendix 1 for details on standard of living index). 
Table 2.1

Profile of respondents

\begin{tabular}{|c|c|c|}
\hline Characteristics & $\begin{array}{c}\text { Vadodara } \\
(\%)\end{array}$ & $\begin{array}{c}\text { Diamond Harbour } \\
(\%)\end{array}$ \\
\hline \multicolumn{3}{|l|}{ Respondent's age } \\
\hline$<=17$ & 21.1 & 19.6 \\
\hline $18-19$ & 35.2 & 39.6 \\
\hline $20-24$ & 39.7 & 35.0 \\
\hline $25 \&$ above & 4.0 & 5.8 \\
\hline \multicolumn{3}{|l|}{ Husband's age } \\
\hline$<=19$ & 15.1 & 3.5 \\
\hline $20-24$ & 64.7 & 39.5 \\
\hline $25 \&$ above & 20.3 & 57.0 \\
\hline \multicolumn{3}{|l|}{ Current status } \\
\hline Newly married & 37.0 & 31.8 \\
\hline First-time pregnant & 11.2 & 13.8 \\
\hline First-time mother & 51.8 & 54.4 \\
\hline \multicolumn{3}{|l|}{ Years of schooling completed } \\
\hline None & 13.4 & 20.9 \\
\hline Up to 5 & 30.1 & 35.3 \\
\hline $6-8$ & 38.6 & 27.3 \\
\hline $9 \&$ above & 17.9 & 16.5 \\
\hline \multicolumn{3}{|l|}{ Religion } \\
\hline Hindu & 99.4 & 45.5 \\
\hline Muslim & 0.5 & 54.5 \\
\hline \multicolumn{3}{|l|}{ Caste* } \\
\hline Scheduled Caste/Scheduled Tribe & 6.9 & 18.9 \\
\hline Other Backward Castes & 7.8 & 4.6 \\
\hline Others & 85.3 & 76.5 \\
\hline \multicolumn{3}{|l|}{ Residence before marriage } \\
\hline Village & 89.5 & 94.7 \\
\hline Town/city & 10.4 & 5.3 \\
\hline \multicolumn{3}{|l|}{ Type of family } \\
\hline Nuclear & 8.6 & 29.5 \\
\hline Non-nuclear & 91.4 & 70.5 \\
\hline \multicolumn{3}{|l|}{ Standard of Living Index } \\
\hline Low & 10.5 & 44.0 \\
\hline Medium & 59.6 & 46.7 \\
\hline High & 29.9 & 9.3 \\
\hline $\mathbf{N}$ & 1,079 & 1,036 \\
\hline
\end{tabular}

* Muslims are included in the 'others' category, along with non-Scheduled or non backward caste Hindus. 


\section{CHAPTER 3}

\section{Livelihoods, decision-making, mobility and social networks}

To better understand the social and economic context of married young women's lives, the study explored a range of issues, including respondents' livelihood experiences, savings practices, role in household decision-making processes, mobility and peer networks. Findings presented in this chapter highlight the social and economic vulnerability of married young women in both study sites.

Table 3.1

Work Participation

\begin{tabular}{l|c|c|} 
& $\begin{array}{c}\text { Vadodara } \\
(\%)\end{array}$ & $\begin{array}{c}\text { Diamond Harbour } \\
(\%)\end{array}$ \\
\hline Ever worked & 47.9 & 19.4 \\
Currently working & 19.4 & 4.4 \\
\hline Initiation into work & & 17.4 \\
Before marriage & 39.2 & 1.8 \\
After marriage & 8.3 & 17.4 \\
Proportion of women who worked & & 5.1 \\
Before marriage & 39.2 & $\mathbf{1 , 0 3 6}$ \\
\hline After marriage & 26.5 & $\mathbf{1 , 0 7 9}$ \\
\hline $\mathbf{N}$ & & \\
\hline
\end{tabular}

${ }^{1}$ Unpaid and paid work includes women's participation in activities for which they were paid in cash or kind (including selling things or work in a small business), and work for which they may not have been paid (including work on the family farm or for the family business).

\section{Work participation}

In India, for many girls, adolescence marks their initiation into economic roles. Data on married young women's paid or unpaid work participation ${ }^{1}$ in the study sites show significant differences. A larger proportion of women in Vadodara than in Diamond Harbour had ever engaged in paid or unpaid work (see Table 3.1). A much smaller proportion of women were currently working (i.e., in the 6 months prior to the survey) compared to those who reported having ever worked in both sites. 
Data also reflect significant changes in married young women's work participation following marriage. In both sites, a larger proportion of women reported initiation into paid or unpaid work before marriage than after marriage (39 percent versus 8 percent in Vadodara; 17 percent versus 2 percent in Diamond Harbour); and work participation declined following marriage, particularly in Diamond Harbour (39 percent versus 27 percent in Vadodara; 17 percent versus 5 percent in Diamond Harbour). As 95 percent of the study participants were under age 25 , we acknowledge that the period of exposure for initiating economic activity after marriage is truncated and thus, while the data are indicative of this particular population, they are not reflective of their life course.

\section{Persons influencing decisions regarding married young women's work participation}

All respondents, irrespective of their work status, were asked who influenced the decision about whether or not they could work (Figure 3.1). The majority of young women in both sites reported that work-related decisions rested with other family members, though more women in Diamond Harbour than in Vadodara felt that they had a significant say in the decision.

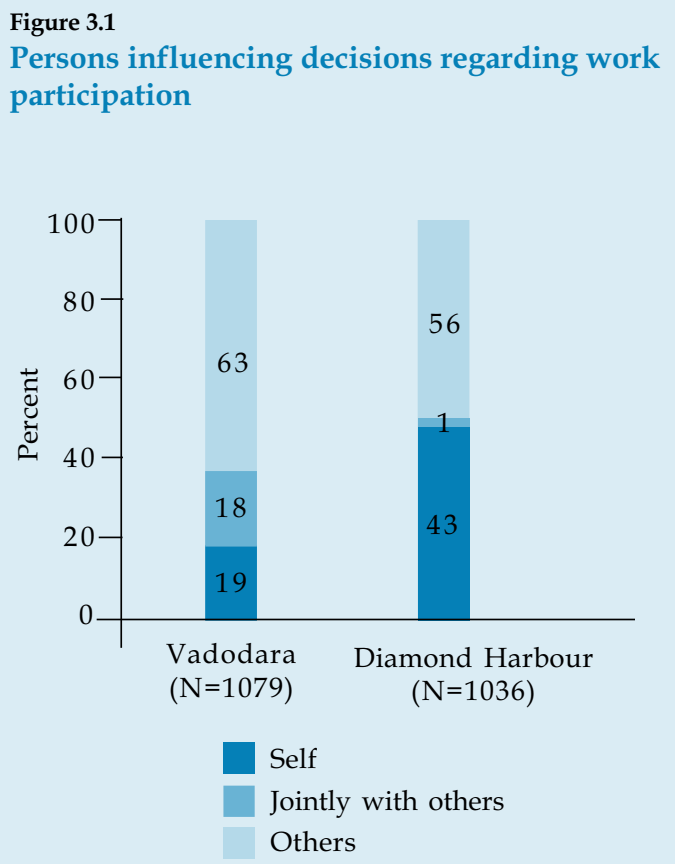

Self

Jointly with others Others

\section{Management of earnings}

Among married young women who reported having ever earned cash, control over their earnings varied significantly between the sites (Figure 3.2). An overwhelming proportion (over 80 percent) in Vadodara, compared to just under half (48 percent) in Diamond Harbour, handed over all their earnings to others. 


\section{Figure 3.2 \\ Management of earnings}

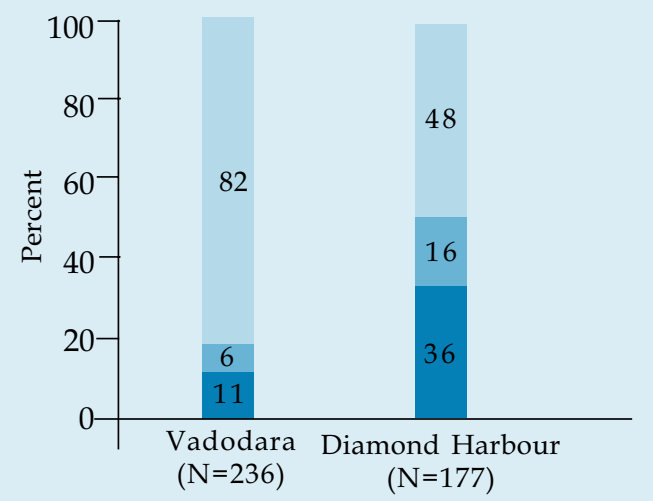

Kept all to self

Gave some away

Gave all away

Note : Includes respondents who were paid entirely or partly in cash out of those who ever worked.

\section{Savings practice}

Respondents were asked whether they had ever saved, whether they currently save and where they keep their savings. A comparatively larger proportion of married young women in Vadodara than in Diamond Harbour reported having ever saved money (44 percent versus 19 percent; $\mathrm{p}=0.000)$; this difference may be because a larger proportion of married young women worked and were given money to spend or manage in Vadodara than in Diamond Harbour.
Compared to those who ever saved, fewer married young women reported current savings in both sites, particularly in Diamond Harbour (26 percent in Vadodara versus 9 percent in Diamond Harbour; $p=0.000$ ). In both sites, the vast majority of those who ever saved money kept their savings in a 'safe place' at home or gave them to someone for safekeeping (87 percent in Vadodara and 71 percent in Diamond Harbour; see Figure 3.3). A relatively larger proportion of women in Diamond Harbour than in Vadodara (24 percent versus 10 percent) saved with formal savings institutions including banks, post offices, women's self-help groups or cooperatives.
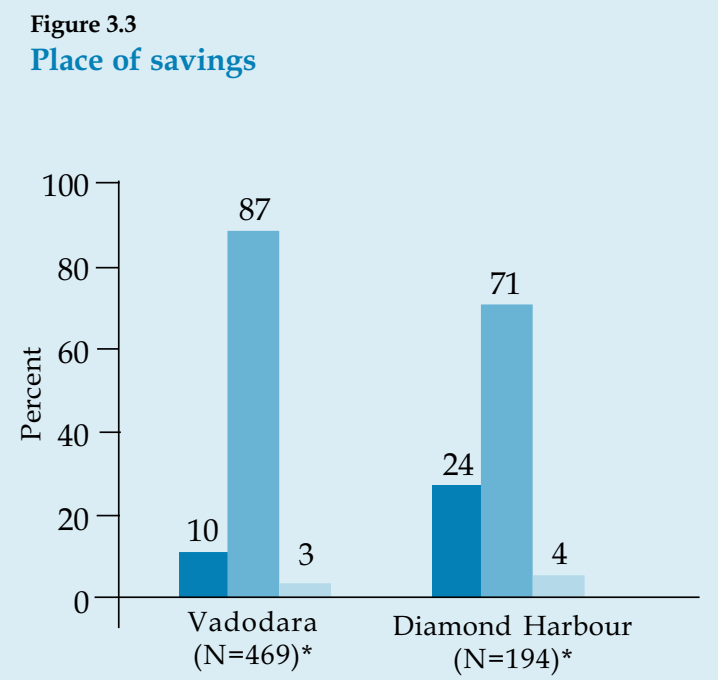

Formal institutions Informal saving options Formal and informal

* includes respondents who saved money 


\section{Household-related decision-making}

In both sites, the majority of married young women did not have a say in decisions related to the purchase of various household items (see Figure 3.4). At the same time, there are significant differences between the sites. Women in Vadodara were less likely to have a say in household decisions compared to those in Diamond Harbour; for example, more than three-fourths of women in Vadodara reported that they had no say in decisions regarding the purchase of food compared to three-fifths in Diamond Harbour $(\mathrm{p}=0.000)$.

\section{Mobility}

In both sites, married young women's mobility is extremely limited. The vast majority of women could not go unescorted to specific destinations even if permission had been granted (Figure 3.5). Only 30 percent of women reported that they could go alone to visit a friend or relative residing in their village if permission to visit them had been obtained. The proportion was as low as 5 percent when visiting an NGO/ government programme was considered.

\section{Figure 3.4}

Persons influencing household-related decisions

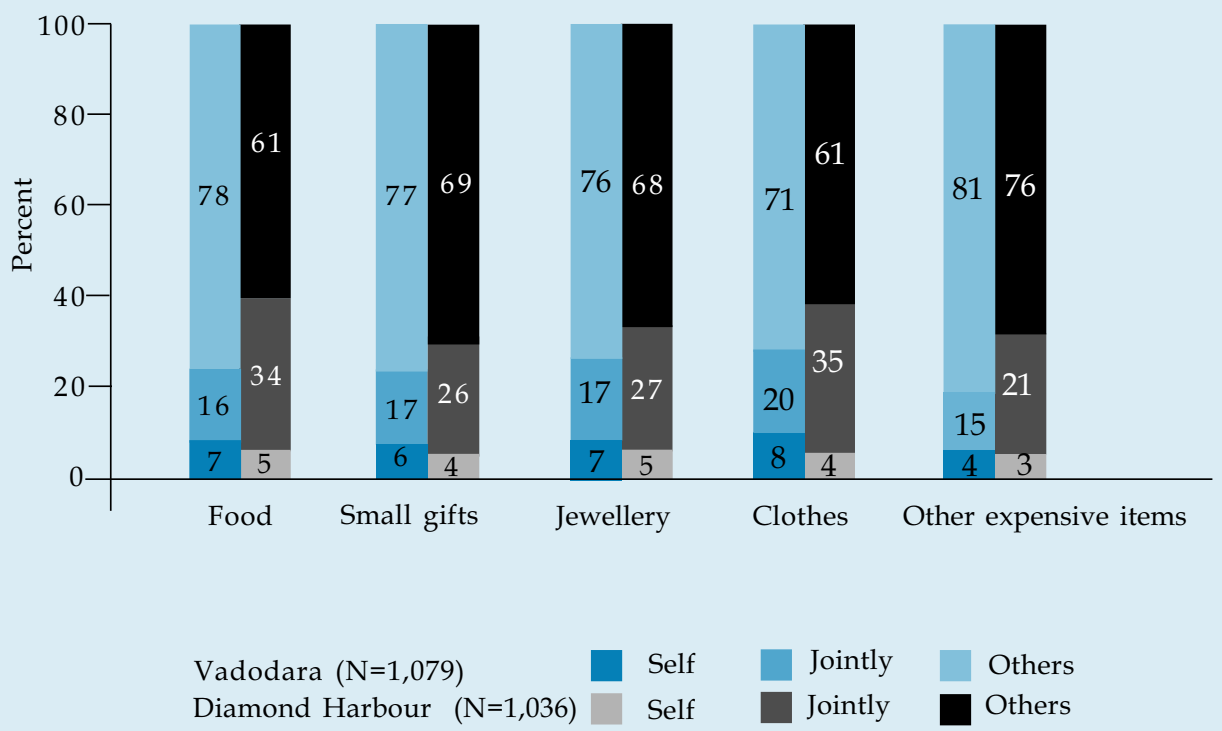


Figure 3.5

Percentage of young married women who could go unescorted to selected destinations

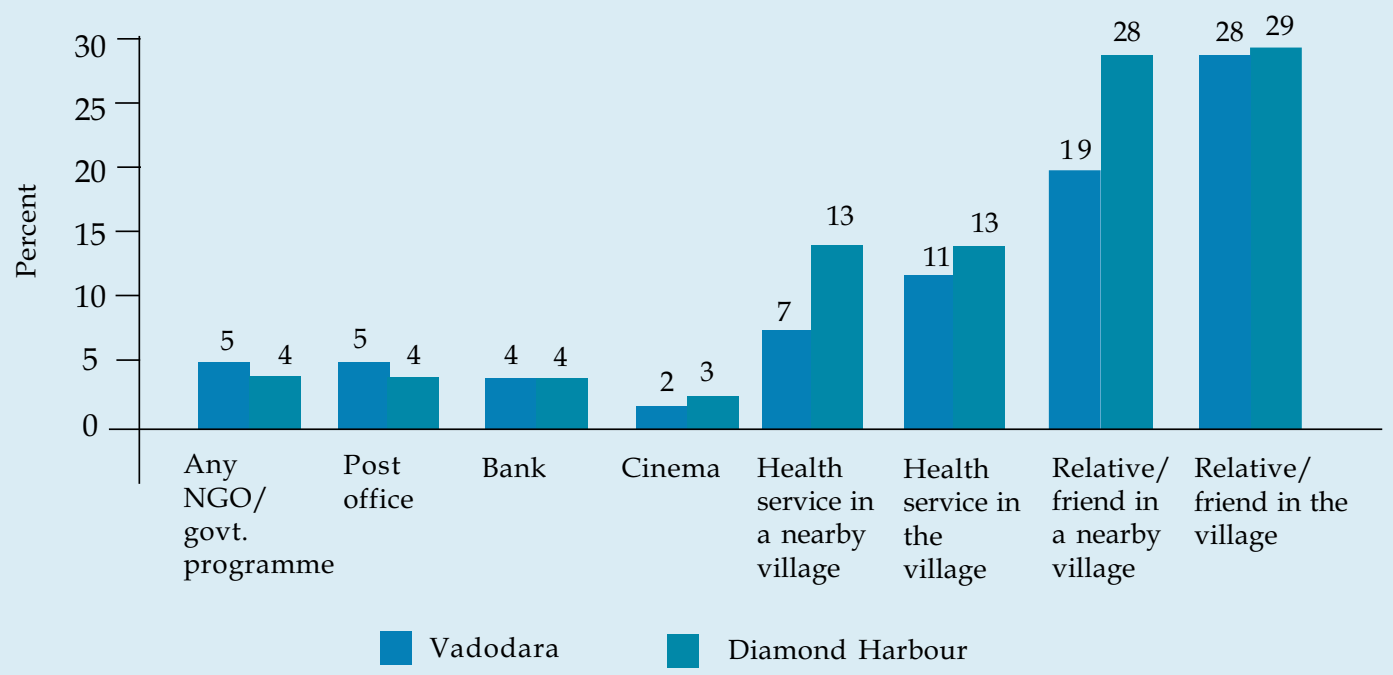

Note: Respondents who reported that the above-listed destinations did not exist were excluded from the analysis. The percentage of respondents thus excluded is in the range of 0-2 percent in Vadodara and 0-11 percent in Diamond Harbour, depending on the destination

\section{Exposure to mass media}

More than two-thirds of married young women in both sites reported regular exposure to at least one type of mass media (Figure 3.6). In Vadodara, television had a much greater reach than other media, with nearly three in five women reporting regular exposure to television. In Diamond Harbour, on the other hand, the radio had a much greater reach, with nearly three in five women reporting regular exposure to the radio.

\section{Social networks}

In both sites, the majority of married young women maintained regular connections with members of their natal family; they either visited them or received visits from them regularly (Table 3.2). In contrast, they had limited contact with nonfamilial peers or friends in their marital villages, particularly in Diamond Harbour. While the majority of women reported having friends in their natal village, only 25 percent in Vadodara 
and 7 percent in Diamond Harbour reported having friends in their marital village (Table 3.2). They also reported limited interaction with these friends, particularly in Vadodara where less than 25 percent reported meeting their friends often; compared to Diamond Harbour, where 40 percent of those who had friends in their marital village reported meeting them often. Notably, in both sites, married young women's association with community groups and organisations was negligible, with fewer than 2 percent reporting membership of a community group or organisation. Moreover, in both sites, respondents benefited only marginally from NGO programmes; clearly, existing programmes are not reaching this population.

Figure 3.6

Regular exposure to mass media

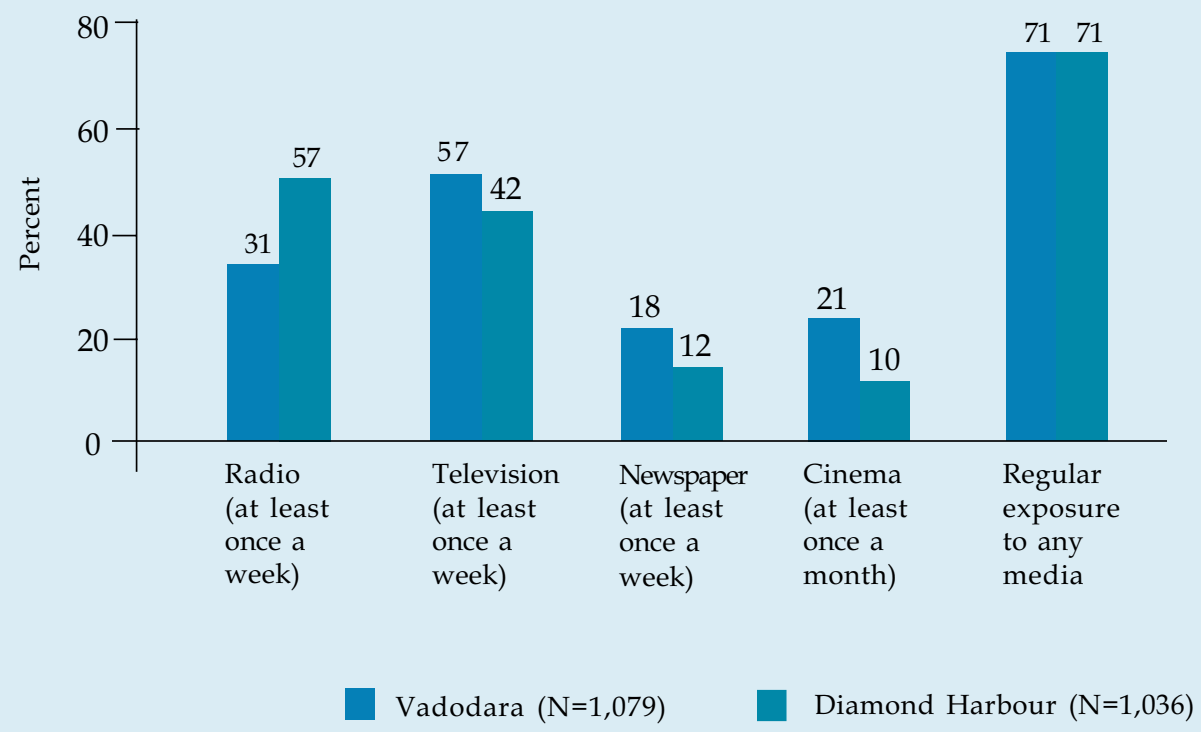


Table 3.2

Connections with natal home, non-familial peers and community groups/ organisations

\begin{tabular}{|c|c|c|}
\hline & $\begin{array}{c}\text { Vadodara } \\
(\%)\end{array}$ & $\begin{array}{c}\text { Diamond Harbour } \\
(\%)\end{array}$ \\
\hline \multicolumn{3}{|l|}{ Connections with natal family } \\
\hline \multicolumn{3}{|c|}{ Frequency of women visiting natal family* } \\
\hline Rarely** & 28.7 & 48.7 \\
\hline Frequently & 57.9 & 41.2 \\
\hline Very frequently & 13.5 & 10.1 \\
\hline \multicolumn{3}{|c|}{ Frequency of visits by natal family members* } \\
\hline Not at all & 3.0 & 5.0 \\
\hline Rarely & 25.3 & 42.0 \\
\hline Frequently & 59.8 & 40.0 \\
\hline Very frequently & 11.9 & 13.0 \\
\hline \multicolumn{3}{|c|}{ Connections with non-familial peers } \\
\hline Having friends in natal village & 96.1 & 67.4 \\
\hline Having friends in marital village & 25.1 & 6.8 \\
\hline \multicolumn{3}{|c|}{ Frequency of interaction with peers in marital village ${ }^{* * *}$} \\
\hline Rarely & 17.0 & 15.9 \\
\hline Occasionally & 59.6 & 44.4 \\
\hline Often & 23.4 & 39.7 \\
\hline \multicolumn{3}{|c|}{ Connections with community groups/organisations } \\
\hline Member of a group/club & 1.6 & 0.7 \\
\hline Beneficiary of NGO programme & 3.7 & 2.9 \\
\hline $\mathbf{N}$ & 1,079 & 1,036 \\
\hline
\end{tabular}

* Excludes 9 women in Vadodara and 36 in Diamond Harbour who reported that they usually resided in their natal home.

** Includes 1 percent who reported that they never visited their natal home.

${ }^{* * *}$ Denominator is women who reported having friends in their marital village. 


\section{CHAPTER 4}

\section{Gender role attitudes, and perceptions and experience of domestic violence}

Attitudes and beliefs regarding gender norms may preclude or inhibit many women from exercising choice or informed consent in decisions concerning their lives. This chapter presents survey findings on married young women's gender role attitudes and their perceptions and experience of domestic violence.

\section{Gender role attitudes}

A large proportion of married young women had egalitarian gender role attitudes with respect to women's freedom to work and husbands sharing the responsibility of household chores (Table 4.1). Yet, for other norms, such as a young woman's right to decide when and whom to marry, whether a woman must accept her husband's decision, and girls' schooling, the vast majority of respondents adhered to traditional gender role attitudes, especially in Vadodara.

A summary index of gender role attitudes was calculated based on the statements in Table 4.1. ${ }^{2}$ As shown in Figure 4.1, data indicate that older women (i.e. age 20 years and older) were

Table 4.1

Gender role attitudes

\begin{tabular}{|c|c|c|}
\hline & $\begin{array}{l}\text { Vadodara } \\
(\%)\end{array}$ & $\begin{array}{l}\text { Diamond Harbour } \\
(\%)\end{array}$ \\
\hline $\begin{array}{l}\text { Agree that a husband should help with the children and } \\
\text { household chores }\end{array}$ & 92.0 & 94.9 \\
\hline Agree that a woman should be allowed to work & 76.3 & 88.1 \\
\hline $\begin{array}{l}\text { Agree that girls should be allowed to decide when and whom } \\
\text { they want to marry }\end{array}$ & 46.6 & 22.4 \\
\hline $\begin{array}{l}\text { Disagree that husband should decide how household money } \\
\text { is spent }\end{array}$ & 41.1 & 21.7 \\
\hline $\begin{array}{l}\text { Disagree that when money is scarce and a family cannot send } \\
\text { all children to school, boys should be sent before girls }\end{array}$ & 36.9 & 69.9 \\
\hline $\begin{array}{l}\text { Disagree that during a woman's labour/childbirth there is } \\
\text { no role that husband can play }\end{array}$ & 24.9 & 69.8 \\
\hline $\begin{array}{l}\text { Disagree that if a woman's opinion differs with her husband's } \\
\text { opinion, she must accept his opinion }\end{array}$ & 21.2 & 36.5 \\
\hline $\mathbf{N}$ & 1,079 & 1,036 \\
\hline
\end{tabular}

2 The index was calculated by giving a score of 1 for each gender egalitarian norm and a score of 0 for every traditional gender norm. The value of the index ranged from 0 to 7 . A score of 0-3 is classified as representing predominantly traditional attitudes and a score of 4-7 as representing egalitarian attitudes. 
Figure 4.1

Married young women reporting egalitarian gender attitudes by age group

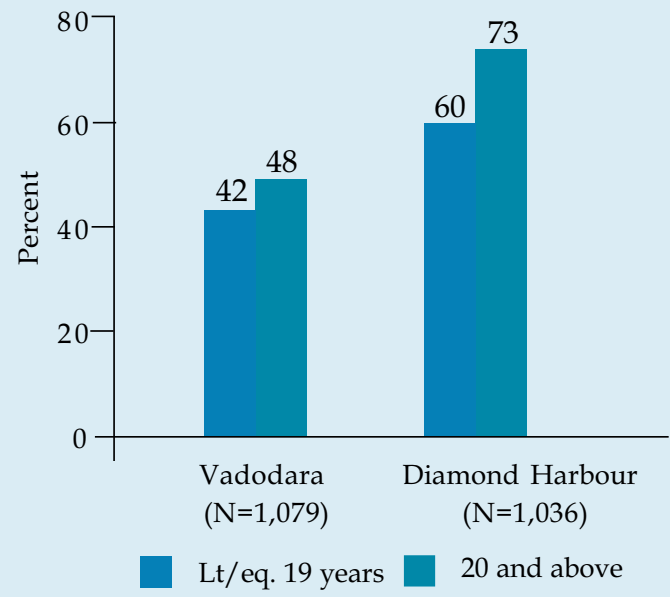

significantly more likely to hold egalitarian gender role attitudes than younger women $(p=0.034$ in Vadodara and $\mathrm{p}=0.000$ in Diamond Harbour).

\section{Perceptions and experience of domestic violence}

Data reflect widespread acceptance of wifebeating among young married women in both sites, especially Diamond Harbour (Figure 4.2). Only 31 percent of women in Vadodara and 13 percent in Diamond Harbour felt that wife-beating is not justified for any of the reasons mentioned. In both sites, young women were most likely to agree that wife-beating is justified if the husband suspects the wife of being unfaithful- almost one-

Figure 4.2

Married young women who agreed with reasons for wife-beating

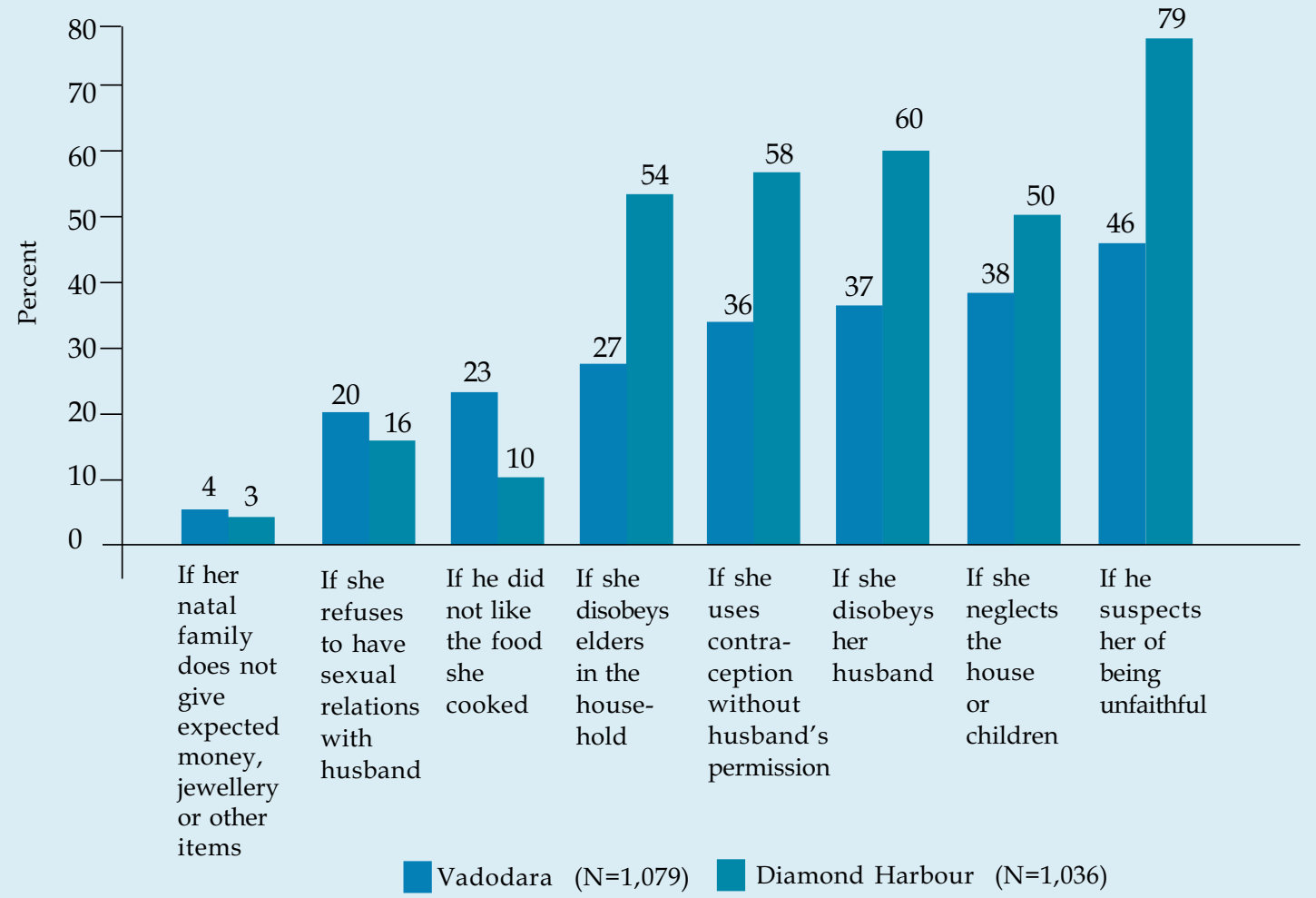


half (46 percent) in Vadodara and nearly fourfifths (79 percent) in Diamond Harbour. Married young women were least likely to agree that a husband is justified in beating his wife for not paying expected dowry.

In Vadodara and Diamond Harbour, 7.4 percent and 12.3 percent, respectively, of married young women reported that they experienced physical harm in the year prior to the survey. An overwhelming majority of these women were abused by their husbands (92 percent of the women who reported physical harm in Vadodara and 86 percent in Diamond Harbour); in Diamond Harbour, a sizeable proportion (over one in five) of women who experienced physical harm also mentioned the mother-in-law as the perpetuator. 


\section{CHAPTER 5}

\section{The marriage process}

Marriage is a rite of passage that brings substantial changes to the lives of a large number of girls and young women in India. It also marks the beginning of socially-sanctioned sexual relations and pressure to have a child. Relatively little is known about the nature of the transition to marriage and its impact on young women's situation in India. This chapter presents study findings regarding various aspects of the transition to marriage as well as the transition to sexual life.

\section{Transition to marriage}

As expected, the vast majority of women in both Vadodara and Diamond Harbour were married at a young age. The median age at marriage for all respondents was 17 years in both sites. As can be seen from Figure 5.1, marriage at a young age was relatively more common in Vadodara than in Diamond Harbour. Among women aged 20-24, a little less than 10 percent were married by age 15 in Vadodara compared to less than 5 percent in Diamond Harbour. By age 18, 54 percent of $20-$ 24-year-old respondents in Vadodara and 49 percent in Diamond Harbour were married. In both sites, many young women felt they were married too early, particularly in Diamond Harbour (nearly three in five in Diamond Harbour and two in five in Vadodara).

Husbands were typically older than their wives at the time of marriage. Most men were married after the age of 18 , i.e., past childhood as

Figure 5.1

Percentage of 20-24-year-old women married by exact ages

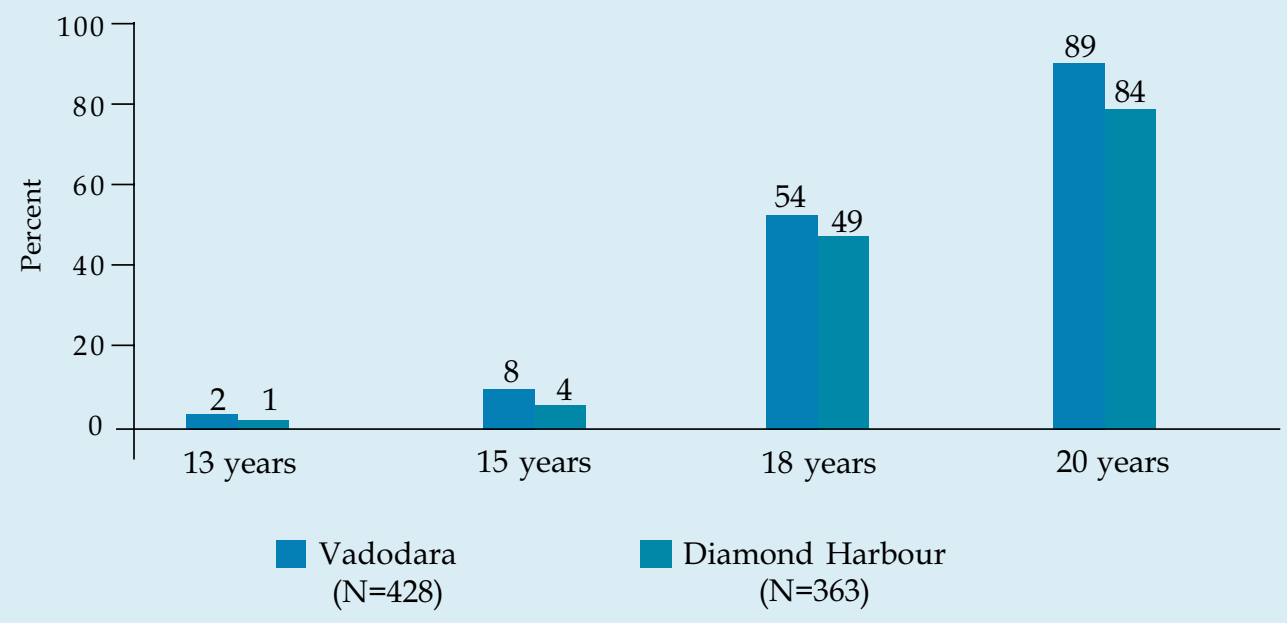


defined by the Convention on the Rights of the Child, yet a sizable proportion were married before the age of 21, the legal minimum age at marriage for men in India. The median age at marriage for husbands was 20 years in Vadodara, compared to 23 years in Diamond Harbour ${ }^{3}$. Data indicate that the spousal age difference varies markedly between the two sites. The median age difference was 2 years in Vadodara as compared to 6 years in Diamond Harbour (see Figure 5.2).

In India, while age at marriage in some settings precedes age at cohabitation with the spouse by a considerable number of years, in both study sites the median age at cohabitation was the same as age at marriage.
In both study sites, most marriages are arranged and young women appear to have little say in the choice of partner. Indeed, in Vadodara, nearly all marriages (98 percent) were arranged. However, in Diamond Harbour, while 86 percent of marriages were arranged, one in seven women also reported a 'love marriage.' The majority had not met their prospective husband before marriage (55 percent in Vadodara, and 73 percent in Diamond Harbour). Thus, it is not surprising that the vast majority of women reported that they were not at all familiar with their husband at the time of marriage (this includes those who had never met their prospective husband before marriage) (Figure 5.3).

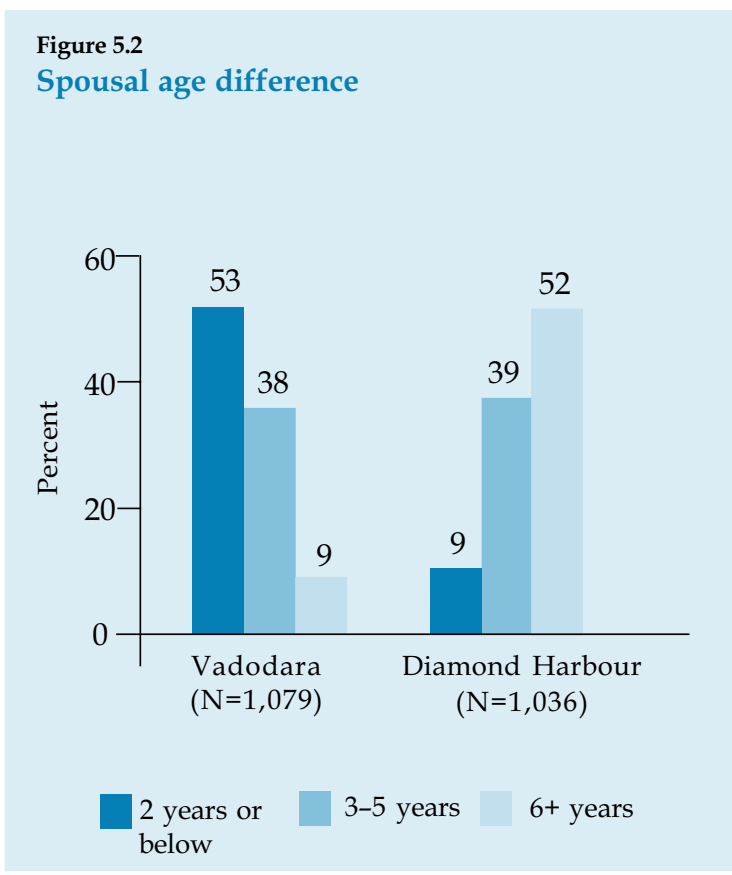

Figure 5.3

Familiarity with husband at the time of marriage

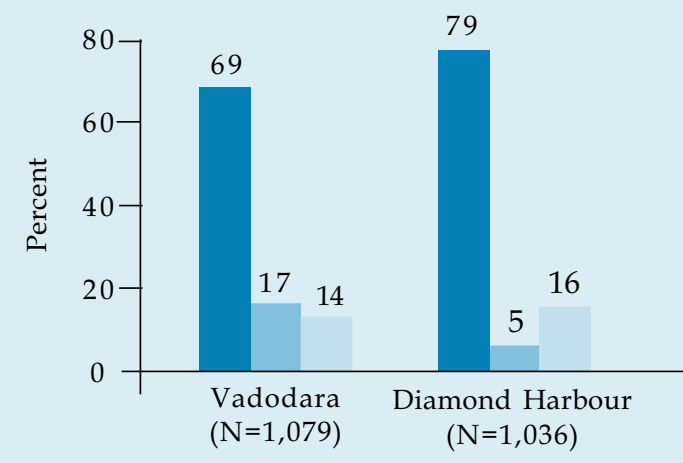

Not at all

\footnotetext{
3 These data may not be entirely accurate as they were gathered from married young women and not directly from their husbands.
} 


\section{Negotiations over and payment of dowry}

Payment of dowry is a salient feature of most marriages in India. The majority of respondents in both sites (62 percent in Vadodara and 73 percent in Diamond Harbour) reported that their families had paid dowry to the groom's family; over one-third of women in Vadodara and nearly one-half in Diamond Harbour reported negotiations over dowry, while some had paid dowry without any negotiation. Jewellery, followed by cash, was the most common item of dowry given in both sites.

The vast majority of married young women (81 percent in Vadodara and 71 percent in Diamond Harbour) reported that they needed the permission of adults in their marital family to use or sell the assets that constituted their dowry. While in Vadodara, husbands and mothers-inlaw mainly controlled dowry assets (51 percent and 37 percent, respectively), in Diamond Harbour, husbands primarily exercised control (86 percent)

\section{Moving into the marital home}

Young women's experiences of moving into the marital home were characterised by feelings of shyness, apprehension, fear, loneliness or unhappiness, particularly in the initial days of marriage, with over three-quarters of respondents in Vadodara (79 percent) and Diamond Harbour (84 percent) reporting at least one of these feelings (see Table 5.1). Most married young women kept to themselves when they felt lonely or sad; only a few (about 10 percent) contacted their natal family, and even fewer (less than 2 percent) sought out a friend. At the same time, nearly one in four women in both sites reported being happy, comfortable, excited or confident in the initial days of marriage.

Table 5.1

Initial feelings on moving into the marital home

\begin{tabular}{|c|c|c|c|c|}
\hline \multirow[t]{2}{*}{ Feelings } & \multicolumn{2}{|c|}{$\begin{array}{c}\text { Vadodara } \\
\qquad(\%)\end{array}$} & \multicolumn{2}{|c|}{$\begin{array}{l}\text { Diamond Harbour } \\
(\%)\end{array}$} \\
\hline & On arrival & $\begin{array}{l}\text { During the } \\
\text { first month }\end{array}$ & On arrival & $\begin{array}{l}\text { During the } \\
\text { first month }\end{array}$ \\
\hline Lonely & 32.4 & 11.7 & 24.7 & 15.2 \\
\hline Like a stranger & 22.5 & 12.0 & -- & 13.5 \\
\hline Unhappy & 22.3 & 4.2 & 0.4 & 0.1 \\
\hline Shy & 21.4 & 3.6 & 60.1 & 39.7 \\
\hline Frightened & 13.8 & 3.7 & 54.2 & 22.5 \\
\hline Apprehensive & 2.9 & 0.7 & 19.7 & 10.1 \\
\hline Happy & 19.6 & 46.6 & 20.0 & 37.8 \\
\hline Comfortable & 8.4 & 42.3 & 3.6 & 20.7 \\
\hline Confident & 3.4 & 17.0 & 1.3 & 2.0 \\
\hline Excited & 0.9 & 1.1 & 1.9 & 1.1 \\
\hline Others & 0.1 & 0.5 & 0.2 & 0.5 \\
\hline $\mathbf{N}$ & 1,079 & 1,079 & 1,036 & 1,036 \\
\hline
\end{tabular}


Over half (58 percent) of the young women in Vadodara and 38 percent in Diamond Harbour reported that they had no one to talk with during their initial days in the marital home. Of those who did have someone to talk to, sisters-in-law, followed by husbands, were the people most commonly reported in Vadodara, while only sisters-in-law were reported in Diamond Harbour.

Despite initial fear and apprehension, many married young women reported adjusting to their new lives fairly quickly, with feelings of happiness and comfort replacing fear and loneliness. After a month, 76 percent of women in Vadodara and 47 percent in Diamond Harbour described their feelings positively.

\section{Transition to sexual life}

As noted earlier, for the vast majority of young women in India, sexual activity takes place within the context of marriage. Most young women are uninformed and unprepared when they make this transition. In Vadodara, the majority of respondents (52 percent) first learned about sex from their husbands while in Diamond Harbour natal family members (38 percent), followed by husbands ( 28 percent), constituted the first source of information on sex (see Figure $5.4)$.

Figure 5.4

Initial source of information on sex

Vadodara

$(\mathrm{N}=1,078)$

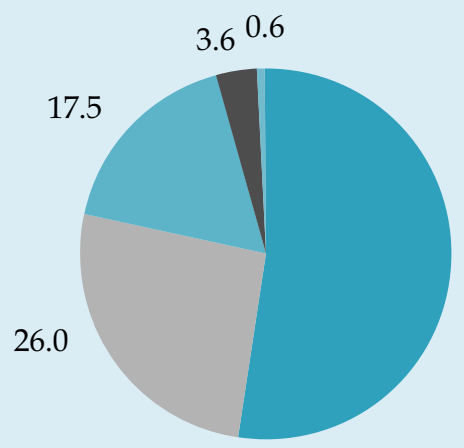

Husband

Others
52.3

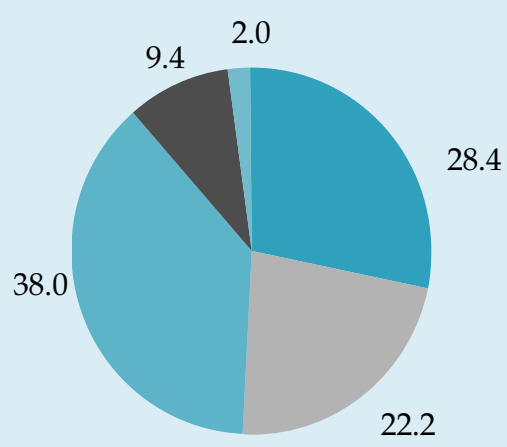

Friend

School/Media
Diamond Harbour

$(\mathrm{N}=1,033)$

28.4

Natal family member 
The median age at sexual initiation reported in both sites -17 years - is the same as the median age at marriage/cohabitation. In both sites, almost all married young women reported that they had their first sexual experience with their husband; only a small minority in Vadodara reported a premarital sexual experience (2.2 percent; 0.9 percent had had sexual relations with their fiancé) while none of the respondents in Diamond Harbour reported such an experience.

In both sites, fear and apprehension were the dominant feelings experienced by the vast majority of married young women (over 70 percent of respondents in Vadodara and 90 percent in Diamond Harbour) before first sexual intercourse. When asked about their feelings after their experience of first sexual intercourse, almost one-half of women in Vadodara and one-third in Diamond Harbour reported that they had liked or enjoyed it. As some women said: 'I was frightened and worried about conceiving, but I enjoyed it.' However, many women, especially in Diamond Harbour, did not enjoy their first sexual experience, or described it as painful or frightening: 'It frightened me so much that I didn't feel like going to him [husband].'

Table 5.2

Feelings before and after first sexual intercourse

\begin{tabular}{|c|c|c|c|c|}
\hline \multirow[t]{2}{*}{ Feelings } & \multicolumn{2}{|c|}{$\begin{array}{l}\text { Vadodara } \\
\qquad(\%)\end{array}$} & \multicolumn{2}{|c|}{$\begin{array}{c}\text { Diamond Harbour } \\
(\%)\end{array}$} \\
\hline & Before & After & Before & After \\
\hline Frightened/scared & 73.9 & 9.4 & 89.8 & 10.2 \\
\hline Curious & 10.7 & -- & 5.7 & -- \\
\hline Excited & 7.6 & 47.8 & 7.6 & 37.4 \\
\hline Not wanting/dislike & 7.1 & 26.9 & 0.2 & 13.0 \\
\hline Apprehensive & 5.8 & -- & 3.8 & -- \\
\hline Shy & 3.3 & 2.7 & 2.5 & 1.1 \\
\hline Nothing special & 1.6 & 1.6 & 0.2 & 1.8 \\
\hline Painful & -- & 14.7 & -- & 39.4 \\
\hline Painful but enjoyed & -- & 3.2 & -- & 6.4 \\
\hline Frieghtening but enjoyed & -- & 1.3 & -- & 1.0 \\
\hline No more fear/shyness & -- & 0.5 & -- & 0.1 \\
\hline Others & 0.7 & 0.6 & 0.1 & 0.5 \\
\hline $\mathbf{N}$ & 1,070 & 1,070 & 1,034 & 1,034 \\
\hline
\end{tabular}




\section{Relationship with spouse}

The survey also explored the nature of the spousal relationship by asking respondents about the amount of time they spend together with their husbands, the extent to which husbands support them in the event of a conflict with other family members, and young women's ability to express their opinion in the event of a disagreement with their husbands.
Data on the amount of time young couples spend together show significant differences between the two sites (Figure 5.5). A larger proportion of married young women in Diamond Harbour than in Vadodara (68 percent versus 42 percent) reported spending time together with their husbands 'frequently' or 'sometimes'. At the same time, a higher proportion of women in Diamond Harbour than in Vadodara (19 percent versus 10 percent) reported that they rarely or never spend time together.

Figure 5.5

Frequency of spending time together with husbands

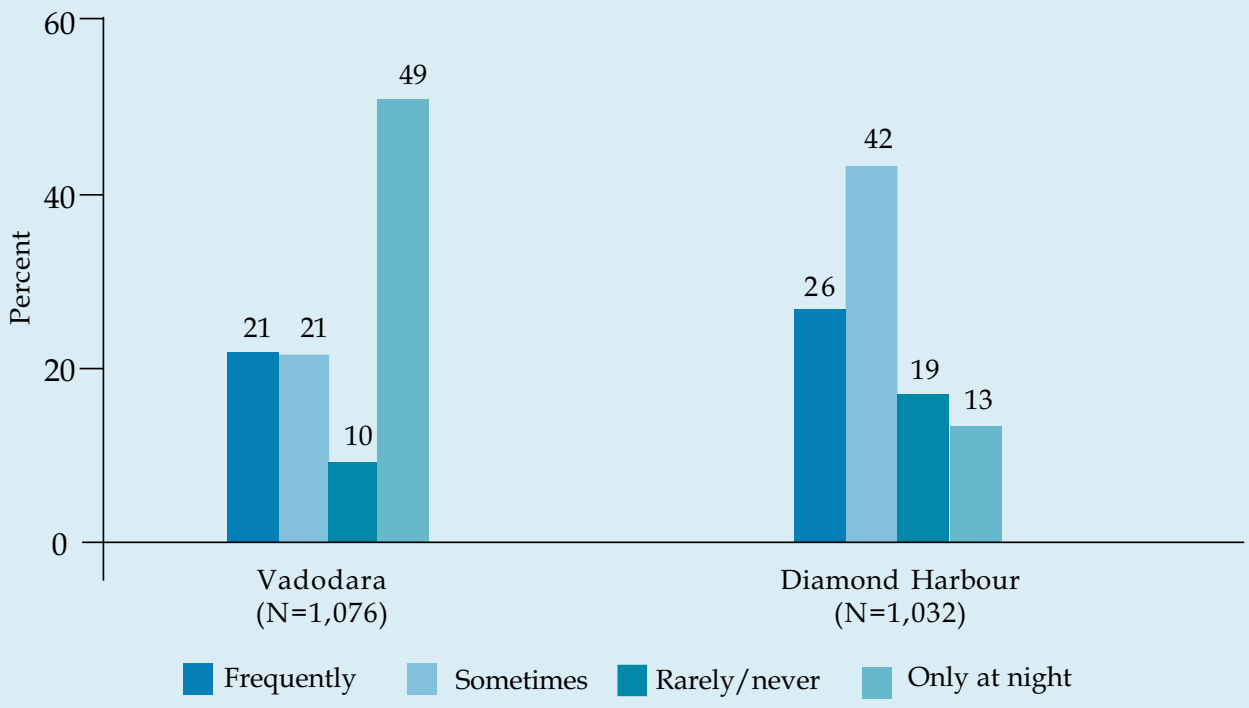


Findings show a dramatic difference in husbands' support of their wives during family conflicts between the two sites. While the majority of married young women in Vadodara reported that their husbands always or frequently

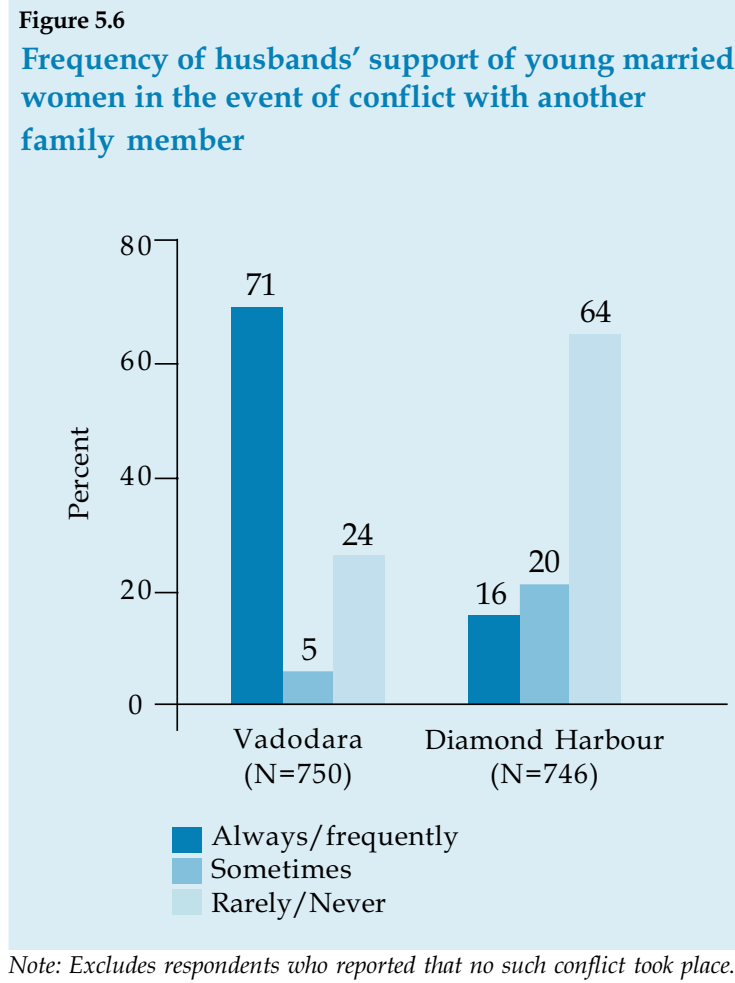

Always/frequently

Sometimes

Rarely/Never

Note: Excludes respondents who reported that no such conflict took place.

supported them in a conflict with a family member, only a minority reported similar support in Diamond Harbour (71 percent versus 16 percent; $\mathrm{p}=0.000$; see Figure 5.6).

A significant proportion of married young women in both sites reported that they were afraid to disagree with their husbands (38 percent in Vadodara and 68 percent in Diamond Harbour, $\mathrm{p}=0.000$ ). However, regardless of their fear of disagreeing with their husbands, a large proportion of respondents in both sites (73 percent in Vadodara and 68 percent in Diamond Harbour) reported telling their husbands when they disagreed with them. First-time mothers in both sites were more likely to express their disagreement than newly-married/ first-time pregnant women, though the association was significant only in Vadodara (77 percent of firsttime mothers versus 67 percent of first-time pregnant women and 68 percent of newly-married women in Vadodara; and 71 percent versus 64 percent and 66 percent respectively in Diamond Harbour). 


\section{CHAPTER 6}

\section{Awareness and knowledge of reproductive health}

Survey findings of the extent of young women's awareness and knowledge of reproductive health matters are discussed in this chapter.

\section{Knowledge of contraceptive methods}

In both sites, basic awareness of spacing methods is generally high. Almost all married young women in Diamond Harbour (98 percent) and 86 percent in Vadodara were aware of at least one spacing method. 4 The oral contraceptive pill, followed by male condoms, was the most commonly known method; three in four women in Vadodara and nearly all women in Diamond Harbour were aware of the pill (see Figure 6.1).

Detailed questions were asked to determine the extent of married young women's knowledge of various methods of contraception. Substantial gaps in knowledge were found regarding most methods (see Figure 6.1). For example, though 75 percent of respondents in Vadodara had heard of

Figure 6.1

Awareness and knowledge of selected contraceptive methods

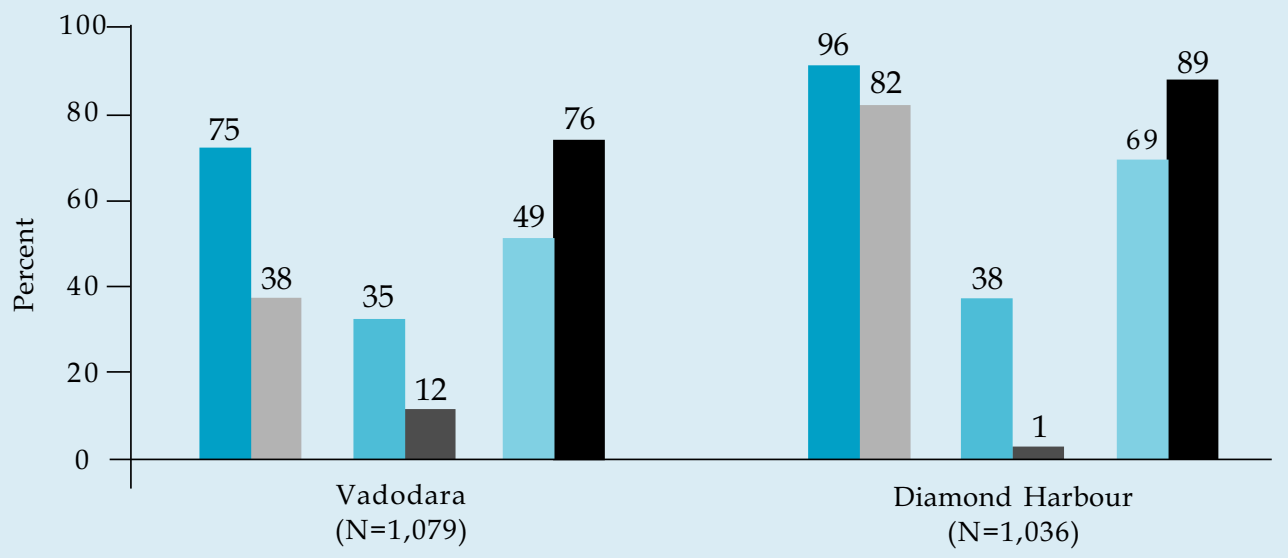

Aware of pill

Correct knowledge of frequency of taking oral pill*

Aware of intra uterine device (IUD)

Correct knowledge of placement of IUD*

Aware of male condom

Correct knowledge of placement of condom *

* Out of those who are aware of the method

${ }^{4}$ As the young women surveyed are in the process of building a family, their awareness and knowledge of spacing methods, and not permanent methods, were explored. 
oral contraceptive pills, only 38 percent knew that the pill should be taken every day. In contrast, while far fewer married young women had heard of male condoms, of those who had heard of this method, most had correct knowledge about it.

\section{Knowledge of the fertile period and determinant of the sex of the baby}

In both study sites, married young women's knowledge about the fertile period is limited. While the majority of women (49 percent in Vadodara and 62 percent Diamond Harbour) were aware of the concept of a fertile period, only 12 percent and 13 percent respectively could accurately identify when a woman's fertile period occurs. Similarly, only a minority of women (18 percent in Vadodara and 17 percent in Diamond Harbour) had correct knowledge about what determines the sex of the baby.

\section{Knowledge of danger signs during pregnancy, delivery, the postpartum period and in newborns}

The vast majority of married young women in both sites had some knowledge (i.e., they could name at least one danger sign) of signs of complications during pregnancy, delivery and the postpartum period as well signs of complications in newborns (Figure 6.2). Of these complications, women were least aware of complications during the postpartum period.

\section{Knowledge of breastfeeding practices}

Findings on married young women's knowledge of the appropriate time to initiate breastfeeding show that a smaller proportion of respondents in Vadodara than in Diamond Harbour (30 percent compared to 59 percent; $\mathrm{p}=0.000$ ) knew that a newborn should be breastfed immediately after birth (see Figure 6.3).

\section{Figure 6.2}

Awareness of complications during pregnancy, delivery, the postpartum period and in newborns

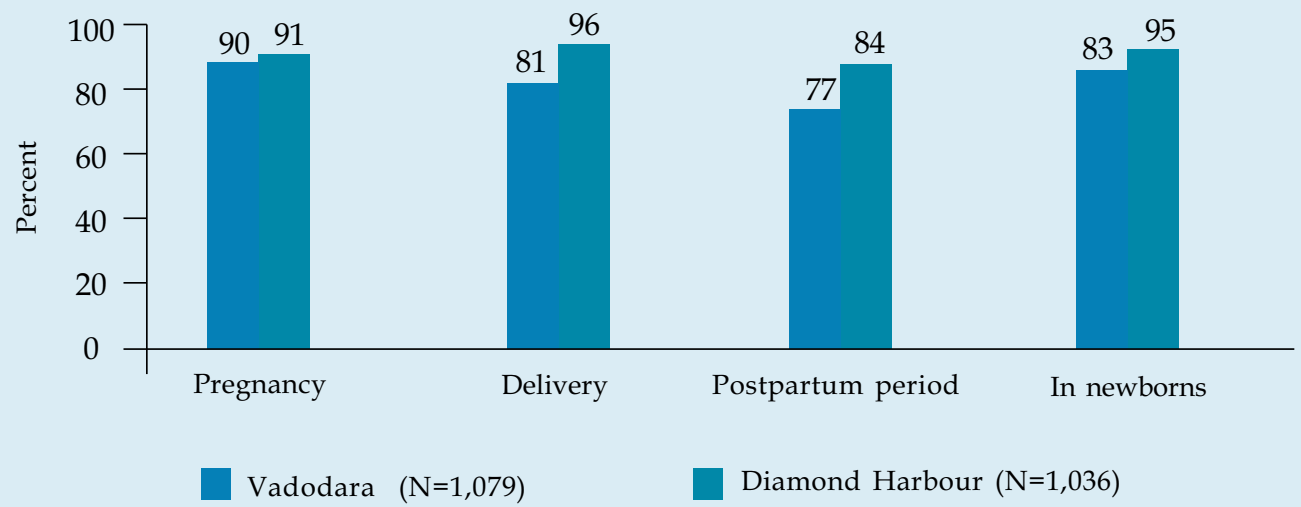


Married young women's knowledge of the importance of feeding colostrum was limited, particularly in Vadodara (28 percent in Vadodara compared to 35 percent in Diamond Harbour; $p=0.000$; see Figure 6.3). While first-time mothers, compared to newly-married or first-time pregnant women, were more aware of the importance of feeding colostrum to a newborn (possibly because of their experience of delivering a baby and likely exposure to messages to feed the newborn colostrum), the proportion who reported such knowledge was low (35 percent in Vadodara and 48 percent in Diamond Harbour). Knowledge of the optimal duration of breastfeeding was higher in Diamond Harbour than Vadodara; one in two married young women in Diamond Harbour

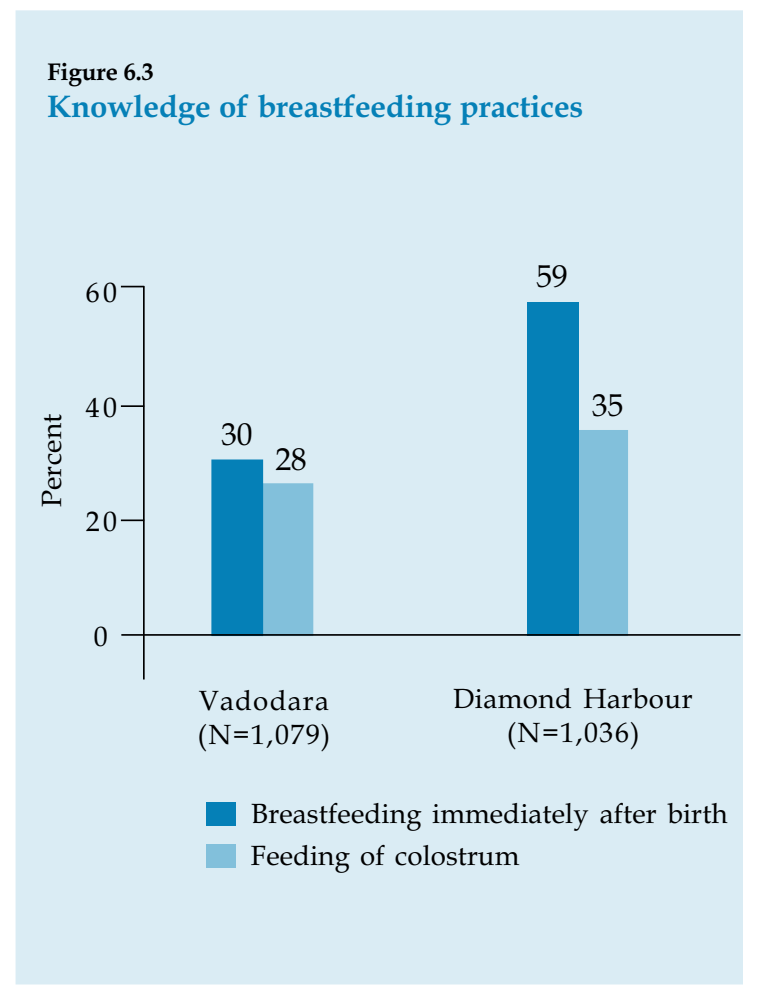

compared to one in five in Vadodara believed that babies should be exclusively breastfed for six months.

\section{Knowledge of sexually transmitted infections and HIV/AIDS}

In both sites, only a minority of married young women (16 percent) had heard of sexually transmitted infections (see Figure 6.4). Of these, the vast majority (three-fourths in Vadodara and four-fifths in Diamond Harbour) knew that it is impossible to tell if another person has a sexually transmitted infection and over 90 percent knew that a husband who has extramarital sex may put his wife at risk of infection.

Figure 6.4
Knowledge of sexually transmitted infections

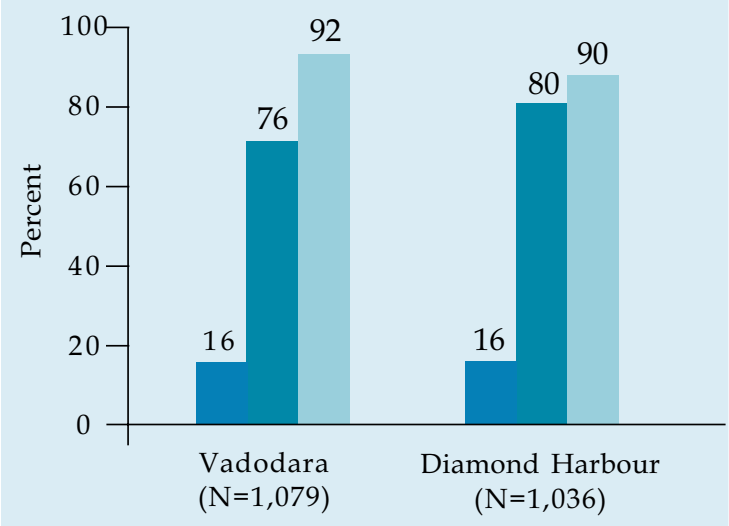

Heard of sexually transmitted infections Believe that it is impossible to tell if somone has STI*

Believe that a husband puts wife at risk if he has sex with another person*

* Out of those who are aware of sexually transmitted infections. 
In both sites, two-thirds of married young women who had heard of sexually transmitted infections were aware of at least one method of preventing the infection, including being faithful to one partner, using a condom for every act of sexual intercourse and sexual abstinence (Table 6.1). Fifteen percent of women in Vadodara and 8 percent in Diamond Harbour reported no knowledge of ways to prevent sexually transmitted infections. Eighteen percent in Vadodara and 22 percent in Diamond Harbour reported misconceptions such as avoiding hugging/ kissing, or avoiding sharing food/ clothes as ways of preventing sexually transmitted infections.
Data show that in both sites, awareness of HIV/AIDS is limited - a little over one in five married young women in Vadodara (22 percent) and slightly less than one in three in Diamond Harbour (31 percent) reported that they had heard of HIV/ AIDS. In both sites, among those who had heard of HIV/AIDS, sexual intercourse with multiple partners was reported as the main mode of transmission of HIV/AIDS (82 percent in Vadodara and 65 percent in Diamond Harbour). Other modes of transmission, such as sharing needles and blood transfusion, were also reported by a substantial proportion of respondents in both sites, especially in Diamond Harbour (data not shown). One in seven respondents in Vadodara

Table 6.1

Perceptions of methods to prevent sexually transmitted infections

\begin{tabular}{|c|c|c|}
\hline $\begin{array}{l}\text { Perceived method of preventing sexually } \\
\text { transmitted infections }\end{array}$ & $\begin{array}{c}\text { Vadodara } \\
(\%)\end{array}$ & $\begin{array}{l}\text { Diamond Harbour } \\
\qquad(\%)\end{array}$ \\
\hline Be faithful to one partner & 45.2 & 27.8 \\
\hline Avoid sex/abstinence & 23.2 & 46.7 \\
\hline Use condom for every sexual intercourse & 22.6 & 24.3 \\
\hline Encourage partner to be faithful & 11.3 & 1.8 \\
\hline Avoid sex worker & 5.6 & 29.0 \\
\hline Apply medicine & 11.3 & - \\
\hline Avoid hugging/kissing & 2.3 & 4.1 \\
\hline Consult doctor & 1.7 & 14.2 \\
\hline Avoid sharing food/clothes & 1.1 & 1.8 \\
\hline Others & 4.5 & 4.1 \\
\hline Don't know & 14.7 & 8.3 \\
\hline $\mathbf{N}^{*}$ & 176 & 170 \\
\hline
\end{tabular}

* Out of those who have heard of sexually transmitted infections 
and nearly one in five in Diamond Harbour reported no knowledge of the modes of transmission of HIV/AIDS, and a negligible minority reported misconceptions, such as transmission through kissing, casual contact with an infected person, and mosquito and other insect bites.

In Vadodara, being faithful to one partner was most commonly reported way to prevent HIV/ AIDS, with more than one-half of women reporting this method among those who had heard of HIV/AIDS (Table 6.2). Other frequently cited modes of prevention included sexual abstinence, encouraging one's partner to remain faithful, and consistent condom use. Nearly one in five married young women reported that they did not know how to prevent HIV/AIDS. In Diamond Harbor, no preventive measure was mentioned by no more than 25 percent of women. Various means including avoiding sex workers, avoiding contaminated blood, sexual abstinence, consistent condom use and not sharing needles were reported by 17-24 percent of women in Diamond Harbour. Nearly one in ten women reported that nothing could be done to prevent $\mathrm{HIV} / \mathrm{AIDS}$, and more than one in five women said that they did not know how to prevent HIV/AIDS.

\section{Interaction with health workers}

Under the Government of India's Reproductive and Child Health (RCH) programme, health workers are expected to provide information to

Table 6.2

Knowledge of ways of preventing HIV/AIDS

\begin{tabular}{|c|c|c|}
\hline Modes of prevention & $\begin{array}{l}\text { Vadodara } \\
(\%)\end{array}$ & $\begin{array}{l}\text { Diamond Harbour } \\
(\%)\end{array}$ \\
\hline Be faithful to one partner & 51.9 & 13.2 \\
\hline Sexual abstinence & 28.1 & 18.9 \\
\hline Encourage partner to be faithful & 19.1 & 6.3 \\
\hline Consistent condom use & 17.4 & 19.8 \\
\hline Avoid contaminated blood & 8.5 & 23.6 \\
\hline Do not share needles & 6.4 & 17.0 \\
\hline Avoid sex workers & 4.7 & 22.3 \\
\hline Non-penetrative sex & 3.0 & 8.5 \\
\hline Others & 2.6 & 9.1 \\
\hline Nothing a person can do & 3.4 & 9.1 \\
\hline Don't know & 17.9 & 22.0 \\
\hline $\mathbf{N}^{*}$ & 237 & 317 \\
\hline
\end{tabular}

* Out of those who have heard of HIV/AIDS 
women on maternal care, birth spacing and immunisation of children during home visits and when women visit the village health centre. In order to assess married young women's access to reproductive health information from this source, respondents were asked whether a health worker had spoken with them about reproductive health issues such as delaying the first pregnancy, care during pregnancy, labour and delivery, postpartum care, breastfeeding and newborn care, spacing the second birth and reproductive tract infections or HIV/AIDS, and whether they had been given any informational materials on these topics. Findings presented in Table 6.3 show that, in general, married young women had limited access to reproductive health information from health workers in both sites, especially in Vadodara. No more than one in five women in Vadodara and two in five women in Diamond Harbour reported that a health worker had spoken with them on any of the above-noted topics, and only a negligible minority (less than 5 percent) in Vadodara reported having received materials on any of these topics. The proportion of respondents who had received any material was comparatively larger in Diamond Harbour, ranging from between one in ten and one in five young women, depending on the topic.

In both sites, the provision of information appeared to be skewed toward prenatal care; health workers were more likely to have discussed care during pregnancy and less likely to have discussed reproductive tract infections/HIV/ AIDS with married young women. For example in Vadodara, and Diamond Harbour, 21 percent and 38 percent, respectively, of women reported that a health worker spoke to them about care during pregnancy, while only 5 percent in Vadodara and 6 percent in Diamond Harbour reported that a health worker spoke to them about reproductive tract infections or HIV/AIDS.

Table 6.3

Percentage of married young women who received information on reproductive health topics from a health worker

\begin{tabular}{l|c|c} 
Topic & $\begin{array}{c}\text { Vadodara } \\
(\%)\end{array}$ & $\begin{array}{c}\text { Diamond Harbour } \\
(\%)\end{array}$ \\
\hline Delaying first pregnancy & 8.7 & 15.6 \\
Care during pregnancy & 21.0 & 37.5 \\
Labour and delivery & 9.5 & 21.1 \\
Postpartum care & 9.7 & 21.9 \\
Breastfeeding and newborn care & 13.3 & 18.9 \\
Spacing second birth & 7.2 & 14.1 \\
Reproductive tract infections/HIV/AIDS & 4.0 & 5.9 \\
\hline $\mathbf{N}$ & $\mathbf{1 , 0 7 8}$ & $\mathbf{1 , 0 3 5}$
\end{tabular}




\section{CHAPTER 7}

\section{Reproductive and sexual health decision-making and practices}

This chapter focuses on the sexual and reproductive health practices of married young women and the extent to which they are able to exercise choice in these matters.

\section{Contraceptive dynamics}

Findings show that ever use of any contraceptive method was limited, particularly in Vadodara (34 percent compared to 48 percent in Diamond Harbour; $p=0.000$; see Figure 7.1). In Vadodara, the most commonly practised methods were the 'safe period' method (14.6 percent) or condoms (13.2 percent), while in Diamond Harbour oral contraceptive pills (31.8 percent) were most frequently used. Given married young women's lack of accurate knowledge of contraceptive methods, as reflected in Figure 6.1, the effective use of these methods is in doubt. For example, of those who reported having practised the safe period method, only 7 percent in Vadodara and 38 percent in Diamond Harbour reported correct knowledge of a woman's fertile period.

Married young women in Vadodara were much less likely to report discussing contraceptive use with their spouse than women in Diamond Harbour (39 percent versus 75 percent; $\mathrm{p}=0.000$ ). Discussion of contraceptive use with other individuals was limited in both sites, particularly in Vadodara (7 percent versus 29 percent; $\mathrm{p}=0.000)$

Findings on who mainly influenced decisions about whether or not to use contraceptive methods (Figure 7.2) indicate that most often, married young women made the decision jointly with other persons (about one-half of women), usually with their husbands. Young women rarely made the decision to use contraception on their own (4 percent in Vadodara and 7 percent in Diamond Harbour). In comparison, 22 percent of husbands in Vadodara and 26 percent in Diamond Harbour made the decision on their own.

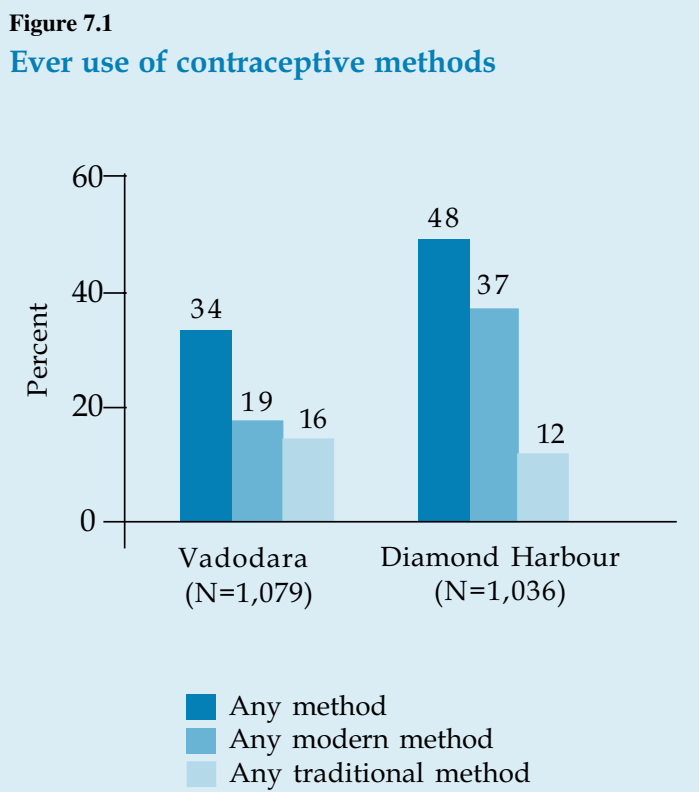




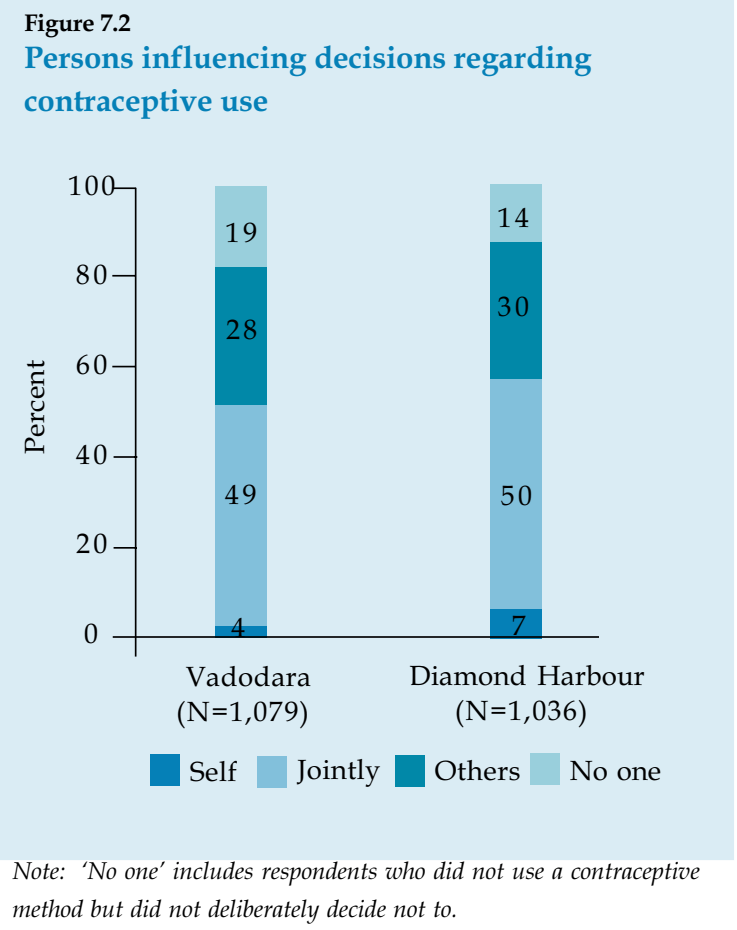

method but did not deliberately decide not to.

\section{Timing of first pregnancy}

Once married, young couples experience enormous family and social pressure to have a child. However, little is known about young couples' preferences regarding timing of the first pregnancy, their role in such decisions, and the extent of communication and negotiation between spouses regarding these decisions.

\section{Preferred timing of first pregnancy}

In both sites, a substantial proportion of married young women (no less than two-fifths) preferred to have their first pregnancy at least two years after marriage (Table 7.1). Data also show that a relatively small proportion of women (no more than one-tenth in Vadodara and a little less than one-fifth in Diamond Harbour) wanted to have a pregnancy within the first year of marriage. Respondents generally reported that their husbands wanted a child earlier in marriage than they themselves did.

In both sites, the desire for time to 'roam around' and young age were the most frequently

Table 7.1

Married young women's and their husbands' preferences regarding the timing of first pregnancy

\begin{tabular}{|c|c|c|c|c|}
\hline \multirow[t]{2}{*}{$\begin{array}{l}\text { Preferred timing of first } \\
\text { pregnancy }\end{array}$} & \multicolumn{2}{|c|}{$\begin{array}{c}\text { Vadodara } \\
(\%)\end{array}$} & \multicolumn{2}{|c|}{$\begin{array}{c}\text { Diamond Harbour } \\
(\%)\end{array}$} \\
\hline & Wife & Husband & Wife & Husband \\
\hline Whenever God gives & 21.7 & 25.6 & 7.5 & 8.5 \\
\hline Within 1 year & 8.5 & 19.3 & 17.3 & 36.6 \\
\hline Between 1-2 years & 22.8 & 20.1 & 26.1 & 18.4 \\
\hline After 2 years & 28.2 & 19.1 & 25.5 & 16.3 \\
\hline After 3 years & 14.2 & 9.0 & 14.9 & 10.1 \\
\hline Others & 4.7 & 4.5 & 8.7 & 7.4 \\
\hline Don't know & & 2.3 & & 2.8 \\
\hline $\mathbf{N}$ & 1,079 & 1,079 & 1,036 & 1,036 \\
\hline
\end{tabular}


Table 7.2

Reasons for wanting to delay the first pregnancy

\begin{tabular}{|c|c|c|c|c|}
\hline \multirow[t]{2}{*}{ Reasons } & \multicolumn{2}{|c|}{$\begin{array}{c}\text { Vadodara } \\
\qquad(\%)\end{array}$} & \multicolumn{2}{|c|}{$\begin{array}{c}\text { Diamond Harbour } \\
(\%)\end{array}$} \\
\hline & Wife & Husband & Wife & Husband \\
\hline To 'roam around' & 64.8 & 65.3 & 47.4 & 42.6 \\
\hline Too young & 43.7 & $28 . .0$ & 62.7 & 40.8 \\
\hline Need time to get to know each other & 7.3 & 6.0 & 15.6 & 9.9 \\
\hline Finances & 7.1 & 9.9 & 15.4 & 33.6 \\
\hline Husband/wife wants to delay birth & 6.5 & 11.0 & 3.6 & 19.8 \\
\hline Health reasons & 1.3 & 0.7 & 10.5 & 4.0 \\
\hline Other family members want to delaybirth & 0.9 & -- & 2.1 & 1.9 \\
\hline Mother-in-law wants to delay birth & 0.5 & 0.7 & 1.2 & 2.1 \\
\hline Others & 9.2 & 7.9 & 6.3 & 5.0 \\
\hline Don't know & 0.1 & 0.9 & -- & 0.4 \\
\hline $\mathbf{N}$ & 751 & 554 & 774 & 524 \\
\hline
\end{tabular}

mentioned reasons for both married young women and their husbands wanting to delay the first pregnancy (see Table 7.2).

\section{Spousal and non-spousal discussion and decision-making about timing of first pregnancy}

While spousal communication about timing of first pregnancy was widespread (84 percent in Vadodara versus 93 percent in Diamond Harbour; $\mathrm{p}=0.000)$, discussions with other persons were limited in both sites, especially in Vadodara ( 9 percent versus 24 percent; $\mathrm{p}=0.000$ ).

Data on who influenced the decision regarding timing of the first pregnancy show that joint decision-making was twice as high in Vadodara than in Diamond Harbour (56 percent versus 24 percent, see Figure 7.3). Young women
Figure 7.3

Persons influencing decisions regarding timing of first pregnancy

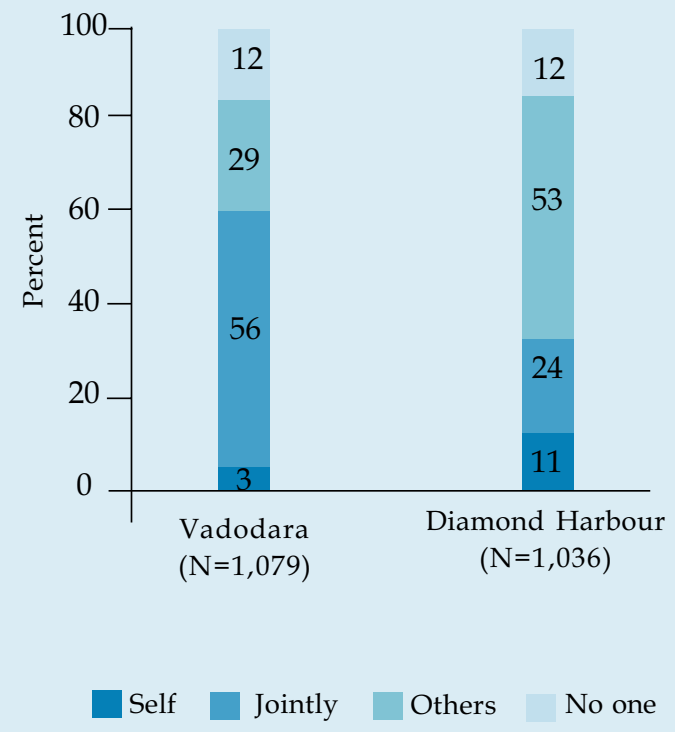


independently had little say in such decisions, especially in Vadodara (3 percent compared to 11 percent in Diamond Harbour). In comparison, 19 percent of husbands in Vadodara and 44 percent in Diamond Harbour made such decisions independently.

\section{Actual timing of first pregnancy}

Childbearing soon after marriage was more common in Diamond Harbour than in Vadodara. Among women who were married for 12 months or more, one-half in Diamond Harbour compared to one-third in Vadodara had their first pregnancy within the first year of marriage (see Figure 7.4). Among those married for 24 months or longer, more than one-half in Vadodara and more than three-fourths in Diamond Harbour had been or had become pregnant for the first time within two years of marriage. One-third of married young women (35 percent) in Vadodara and more than one-half (57 percent) in Diamond Harbour felt that their first pregnancy had occurred too early, and not more than 10 percent of married young women in both sites felt that their first pregnancy occurred too late.

\section{Pregnancy experience}

In order to understand their experiences of first pregnancy, married young women were asked about dietary practice, rest and physical work, sexual behaviour, antenatal check-ups and treatment-seeking practices for complications during pregnancy.
Figure 7.4

Interval between marriage and first pregnancy

Married for $>=12$ months

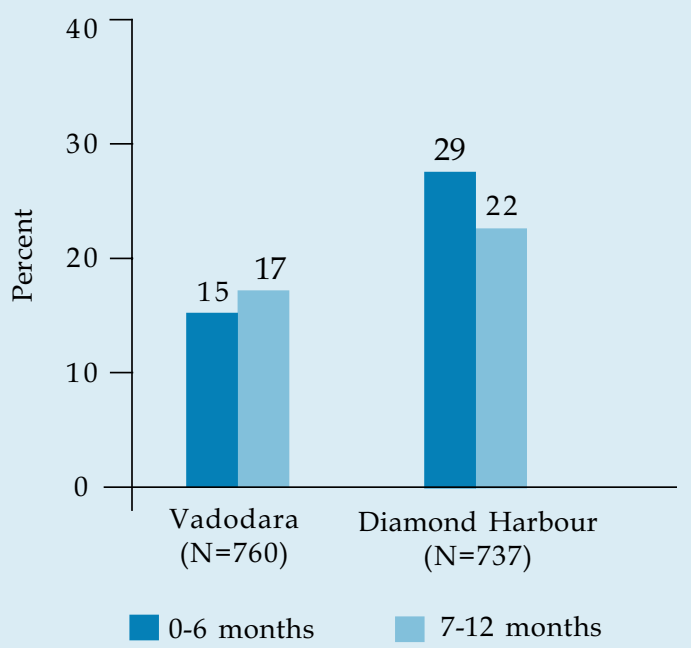

Married for $>=24$ months

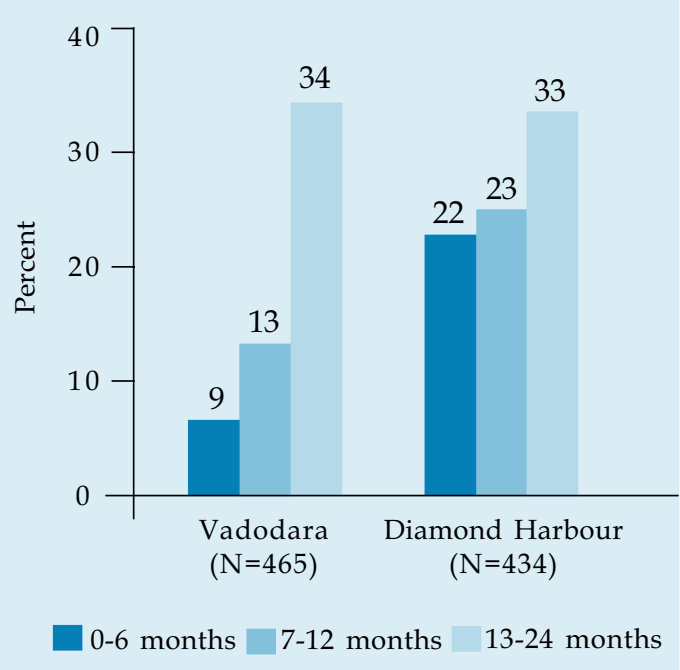




\section{Diet, work and sexual behaviour}

In both sites, most married young women reported changes in diet, work and sexual behaviour during pregnancy. For example, the vast majority (85 percent) of ever-pregnant women in Vadodara had been advised to stop eating certain foods such as milk and milk products, banana and ladyfinger (okra), during their pregnancy, and 84 percent followed such restrictions. Far fewer women in Diamond Harbour (8 percent), in comparison, had been advised dietary restrictions. About one-half of ever-pregnant women in Vadodara and about three-quarters in Diamond Harbour had taken extra rest and/or reduced their physical workload during pregnancy. Roughly 90 percent of everpregnant women in both sites reported that they discussed abstaining from sex during their pregnancy with their husbands; of these, over 90 percent in Vadodara and 85 percent in Diamond Harbour reported that their husbands respected their wishes.

\section{Antenatal check-up}

Receiving at least one antenatal check-up was almost universally reported in both sites, with 93 percent of postpartum women in Vadodara and 97 percent in Diamond Harbour reporting having received at least one such check-up (Table 7.3). However, there are notable differences between the two sites in terms of the timing of the first check-up. In Vadodara, it was more common for postpartum women to have received an antenatal check-up earlier in pregnancy than in Diamond Harbour; more than half (51 percent) of postpartum women in Vadodara, compared to 31 percent in Diamond Harbour, reported receiving their first antenatal check-up in the first trimester of their pregnancy. Data also show that the majority of postpartum women in both sites (55 percent in Vadodara and 60 percent in Diamond Harbour) received at least three antenatal checkups. Information on antenatal services received shows that over 90 percent of postpartum women

Table 7.3

Percentage of married young women who received antenatal check-ups

\begin{tabular}{|c|c|c|}
\hline & $\begin{array}{c}\text { Vadodara } \\
(\%)\end{array}$ & $\begin{array}{l}\text { Diamond Harbour } \\
\qquad(\%)\end{array}$ \\
\hline \multicolumn{3}{|c|}{ Timing of first check-up } \\
\hline First trimester & 51.0 & 30.7 \\
\hline Second trimester & 32.5 & 60.3 \\
\hline Third trimester & 9.3 & 6.2 \\
\hline \multicolumn{3}{|c|}{ Number of check-ups } \\
\hline One & 15.2 & 2.7 \\
\hline Two & 22.9 & 34.8 \\
\hline Three or more & 54.8 & 59.9 \\
\hline No check-up & 7.2 & 2.8 \\
\hline $\mathbf{N}$ & 559 & 564 \\
\hline
\end{tabular}


in both sites were given iron and folic acid supplements and tetanus-toxoid injections.

\section{Delivery experience}

Ninety percent of postpartum women in Diamond Harbour and 61 percent in Vadodara reported having made a delivery plan. The most common component of the delivery plan in both sites was deciding whether to deliver at the respondent's natal or marital home (60 percent of respondents in Vadodara and 88 percent in Diamond Harbour; see Table 7.4). Other frequently made preparations for delivery included identifying a hospital to go to in case of an emergency and saving money to meet the financial expenses of the delivery.

In both settings, it is customary that a woman's first delivery takes place at her natal home. The vast majority of postpartum women in Vadodara (86 percent) and about half in Diamond Harbour (52 percent) reported that they had planned to deliver at their natal home. A larger proportion of women in Vadodara than in Diamond Harbour preferred to deliver in a health facility (59 percent versus 46 percent; $\mathrm{p}=0.000$ ). Sixty-one percent of first births in Vadodara and 50 percent in Diamond Harbour took place in a health facility (see Figure 7.5).

The majority of deliveries (83 percent in Vadodara and 67 percent in Diamond Harbour) were attended by trained health professionals or trained traditional birth attendants. Among women who had a non-institutional delivery, nearly all in Diamond Harbour, compared to twothirds in Vadodara, reported use of a safe delivery kit.

Table 7.4

Arrangements for delivery

\begin{tabular}{|c|c|c|}
\hline Type of arrangement & $\begin{array}{c}\text { Vadodara } \\
(\%)\end{array}$ & $\begin{array}{l}\text { Diamond Harbour } \\
\qquad(\%)\end{array}$ \\
\hline Decided where to deliver (natal/marital home) & 60.0 & 87.9 \\
\hline Identified a hospital to go in case of emergency & 52.8 & 52.6 \\
\hline Saved money to meet delivery expenses & 51.5 & 48.5 \\
\hline Identified/decided hospital & 49.5 & 47.4 \\
\hline Identified mode of transport in case of emergency & 44.9 & 25.9 \\
\hline Discussed plans with close family members & 35.9 & 68.4 \\
\hline Identified/decided traditional birth attendant & 33.3 & 24.5 \\
\hline Kept clean cotton and other necessities ready & 32.3 & 38.5 \\
\hline Others & 1.8 & 4.6 \\
\hline $\mathbf{N}$ & 555 & 563 \\
\hline
\end{tabular}


Figure 7.5

Percentage of married young women who delivered at a health facility

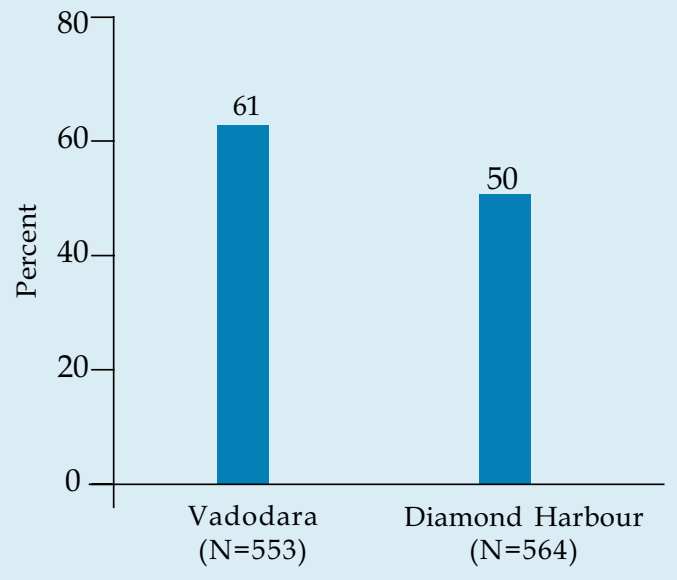

\section{Postpartum experience}

It is customary in both study sites that following delivery, a young woman is kept in 'isolation,' typically in her natal home. This means that the mother, with her newborn, stays separately (for example, in another room) from the rest of the family, does not go out and does little housework apart from washing her own and her baby's clothes. More than 90 percent of mothers in both sites reported that they had observed postpartum isolation for some period of time (Table 7.5). While this practice was common in both sites, the duration of postpartum isolation was longer in Vadodara than in Diamond Harbour; more than two-thirds of mothers observed isolation for more than a month in Vadodara compared to only about one-fourth who observed isolation for a similar period in Diamond Harbour.

Receiving or seeking a routine postpartum check-up was uncommon in both sites, especially in Diamond Harbour (Table 7.6). Only 29 percent of mothers in Vadodara and 8 percent in Diamond Harbour received a routine postpartum check-up. An additional small minority of mothers (5 percent) in Vadodara and 15 percent in Diamond Harbour reported that they were planning to go for a postpartum check-up.

Findings show that of the mothers who received a routine postpartum check-up, a larger proportion in Vadodara received their first checkup soon after delivery compared to mothers in Diamond Harbour (over 50 percent of mothers received a check-up within a week in Vadodara compared to one-fifth in Diamond Harbour). In

Table 7.5

Duration of postpartum isolation

\begin{tabular}{|c|c|c|}
\hline Duration & $\begin{array}{l}\text { Vadodara } \\
\qquad(\%)\end{array}$ & $\begin{array}{l}\text { Diamond Harbour } \\
\qquad(\%)\end{array}$ \\
\hline No isolation & 4.3 & 3.9 \\
\hline Up to 15 days & 3.4 & 21.5 \\
\hline 16-30 days & 21.8 & 51.2 \\
\hline 31-45 days & 65.8 & 20.7 \\
\hline More than 45 days & 4.7 & 2.7 \\
\hline $\mathbf{N}$ & 556 & 564 \\
\hline
\end{tabular}


Table 7.6

Percentage of married young women who received postpartum check-ups

\begin{tabular}{|c|c|c|}
\hline Postpartum check-ups & $\begin{array}{l}\text { Vadodara } \\
\qquad \%)\end{array}$ & $\begin{array}{c}\text { Diamond Harbour } \\
(\%)\end{array}$ \\
\hline Routine check-up & 29.2 & 7.7 \\
\hline Had a check-up but for complications & 15.0 & 16.4 \\
\hline Planning to go for a check-up & 4.8 & 15.4 \\
\hline $\mathbf{N}$ & 548 & 560 \\
\hline \multicolumn{3}{|l|}{ Timing of routine check-up } \\
\hline Within 2 days of delivery & 23.6 & 2.7 \\
\hline 3-7 days & 32.1 & 18.9 \\
\hline $8-30$ days & 40.0 & 67.6 \\
\hline $31-60$ days & 4.3 & 8.1 \\
\hline After 60 days & -- & 2.7 \\
\hline $\mathbf{N}^{*}$ & 140 & 37 \\
\hline
\end{tabular}

both sites, the vast majority of mothers received a routine check-up from private doctors. Though the Reproductive and Child Health programme has recommended three home visits within two months postpartum, data reveal that fewer than one-tenth of mothers who received a check-up in Vadodara received it at home while no mother in Diamond Harbour received a check-up at home.

\section{Breastfeeding practices and immunisation of the baby}

Data show that while breastfeeding is nearly universal, immediate breastfeeding after delivery is relatively limited in both sites, especially in Vadodara. A little over one-fourth of mothers in Vadodara reported immediate breastfeeding compared to over two-fifths in Diamond Harbour $(p=0.000$; see Table 7.7). One-third of mothers reported feeding colostrum to their babies in Vadodara, compared to over one-half in Diamond Harbour.

The vast majority of mothers in both sites (85 percent in Vadodara and 89 percent in Diamond Harbour) reported that their babies had received some immunisation. Among those who had not had their babies immunised, over 80 percent reported that they were planning to do so. 
Table 7.7

Time of initiating breastfeeding and the practice of feeding colostrum

\begin{tabular}{l|c|c} 
& $\begin{array}{c}\text { Vadodara } \\
(\%)\end{array}$ & $\begin{array}{c}\text { Diamond Harbour } \\
(\%)\end{array}$ \\
\hline Time of initiating breastfeeding & & 42.6 \\
Immediately after delivery & 27.6 & 20.4 \\
The day of delivery & 1.6 & 13.7 \\
The day after delivery & 6.9 & 22.3 \\
2 or more days after delivery & 61.9 & 1.1 \\
Did not breastfeed & 2.0 & 53.2 \\
\hline Fed colostrum & & $\mathbf{5 4 . 9}$ \\
\hline $\mathbf{N}$ & $\mathbf{5 5 0}$ & $\mathbf{5 6 4}$
\end{tabular}

Figure 7.6

Self-reported problems/ complications during pregnancy, delivery, the postpartum period and in newborns

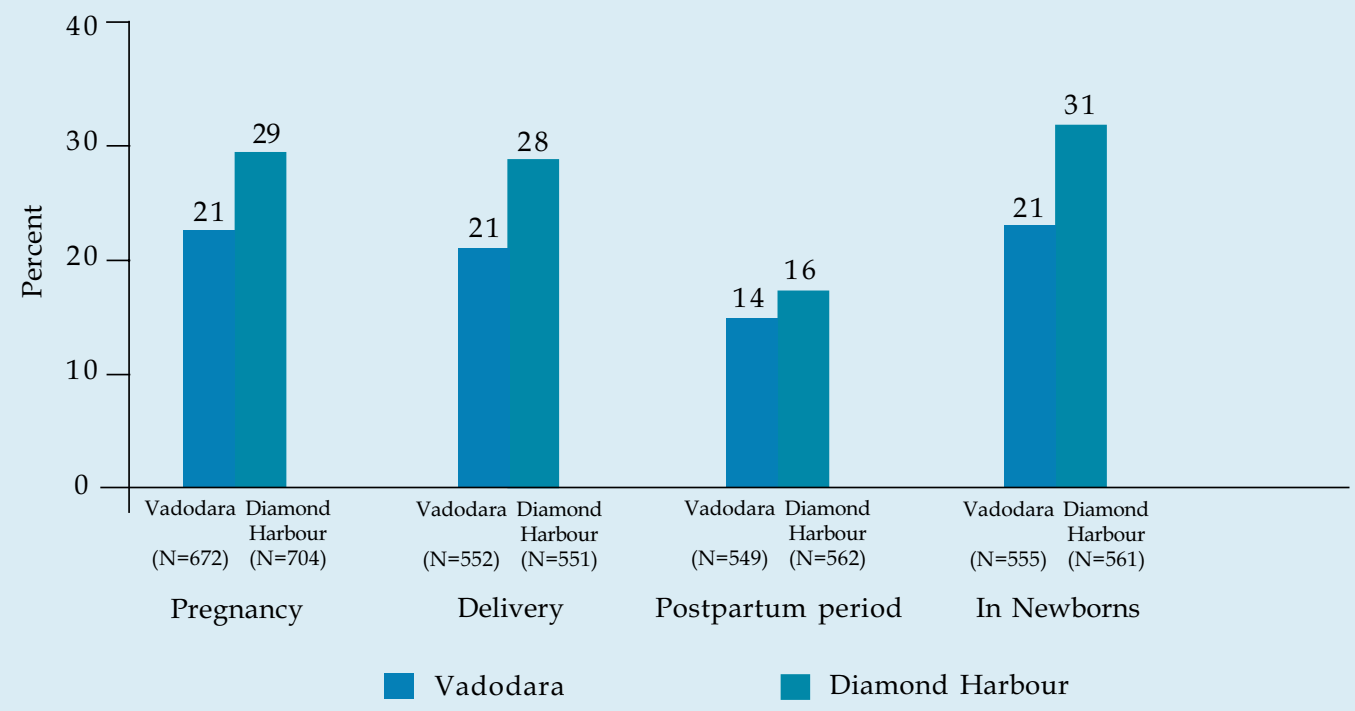

\section{Self-reported complications/problems} during pregnancy, delivery, the postpartum period and in newborns

As can be seen from Figure 7.6, over one-fifth of ever-pregnant women in Vadodara and over one- fourth in Diamond Harbour experienced health problems/complications during pregnancy, and the vast majority had sought treatment (84 percent in Vadodara and 70 percent in Diamond Harbour). Roughly similar proportions of 
postpartum women reported problems/ complications during delivery and in the newborn, and the majority had sought treatment (74 percent in Vadodara and 84 percent in Diamond Harbour for delivery, and 95 percent for their newborn in both sites). Postpartum complications, ranging from fever to fatigue, were relatively less common, according to self-reports.

\section{Beyond the first birth: Desired family size and spacing the second birth}

The vast majority of ever-pregnant women in both sites expressed the desire for a small family. Onetenth of women in Vadodara and one-fifth in Diamond Harbour reported wanting only one child (Table 7.8), and over 85 percent in Vadodara and 59 percent in Diamond Harbour wanted no more than two children.
All ever-pregnant women who reported that they wanted two or more children were asked about the preferred interval between their first and second births. Findings presented in Table 7.9 show that only a small minority in both sites wanted a second child immediately (i.e., within a year or less) after the first child; most preferred a 2-4 year interval between their first and second birth.

Discussions with husbands on spacing the second birth were common in both sites, especially in Diamond Harbour (86 percent compared to 75 percent in Vadodara; $p=0.000)$. Of the everpregnant women who reported no spousal discussion on spacing the second birth, 66 percent in Vadodara and 84 percent in Diamond Harbour reported that they were planning to discuss the issue with their husbands.

\section{Table 7.8}

Desired family size

\begin{tabular}{l|c|c} 
Desired number of children & $\begin{array}{c}\text { Vadodara } \\
(\%)\end{array}$ & $\begin{array}{c}\text { Diamond Harbour } \\
(\%)\end{array}$ \\
\hline One & 9.7 & 20.3 \\
Two & 84.5 & 59.0 \\
Three & 4.1 & 14.0 \\
Four & 0.4 & 4.1 \\
Five or more & -- & 0.3 \\
Whatever God gives & 0.9 & 2.1 \\
Don't know & 0.3 & 0.1 \\
\hline $\mathbf{N}$ & $\mathbf{6 7 7}$ & $\mathbf{7 0 5}$
\end{tabular}


Table 7.9

Preferences regarding interval between first and second birth

\begin{tabular}{l|c|c} 
Preferred interval & $\begin{array}{c}\text { Vadodara } \\
(\%)\end{array}$ \\
$<1$ year & 2.1 & $\begin{array}{c}\text { Diamond Harbour } \\
(\%)\end{array}$ \\
1 year & 13.1 & 0.2 \\
2 years & 33.9 & 0.9 \\
3 years & 17.7 & 11.3 \\
4 years & 6.2 & 68.0 \\
Till the first child can walk & 10.8 & 7.7 \\
Whenever God gives & 10.2 & 2.9 \\
Others & 5.9 & 1.6 \\
\hline $\mathbf{N}$ & $\mathbf{6 1 0}$ & $\mathbf{5 6 0}$
\end{tabular}

A large proportion of ever-pregnant women who wanted more than one child in both sites (61 percent in Vadodara and 57 percent in (Diamond Harbour) reported joint decision-making on spacing the second birth (see Figure 7.7). Only 78 percent of women reported that they independently influenced such decisions, compared to 13-14 percent reporting that their husbands' preference alone influenced such decisions. It is interesting to note that a larger proportion of women reported having some say in decisions related to spacing the second birth compared to women reporting some say in decisions related to timing of the first pregnancy in both sites, especially in Diamond Harbour (see Figure 7.3).
Figure 7.7

Persons influencing decisions regarding spacing the second birth

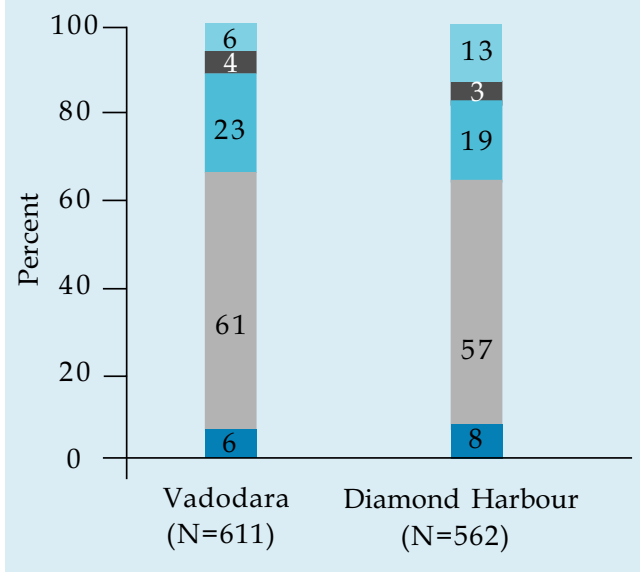

Self

Jointly with others

Others

No one

No decision made yet 


\section{CHAPTER 8}

\section{Support during pregnancy, delivery and the postpartum period}

This chapter discusses survey findings on the extent and type of support married young women received as well as harassment experienced during pregnancy, delivery and in the postpartum period.

\section{Support during pregnancy}

A large proportion of ever-pregnant women in Vadodara and Diamond Harbour reported having received help in doing household chores (83 percent and 78 percent respectively) and in accessing health services (85 percent and 91 percent), as well as getting emotional support (97 percent and 92 percent) during their pregnancy

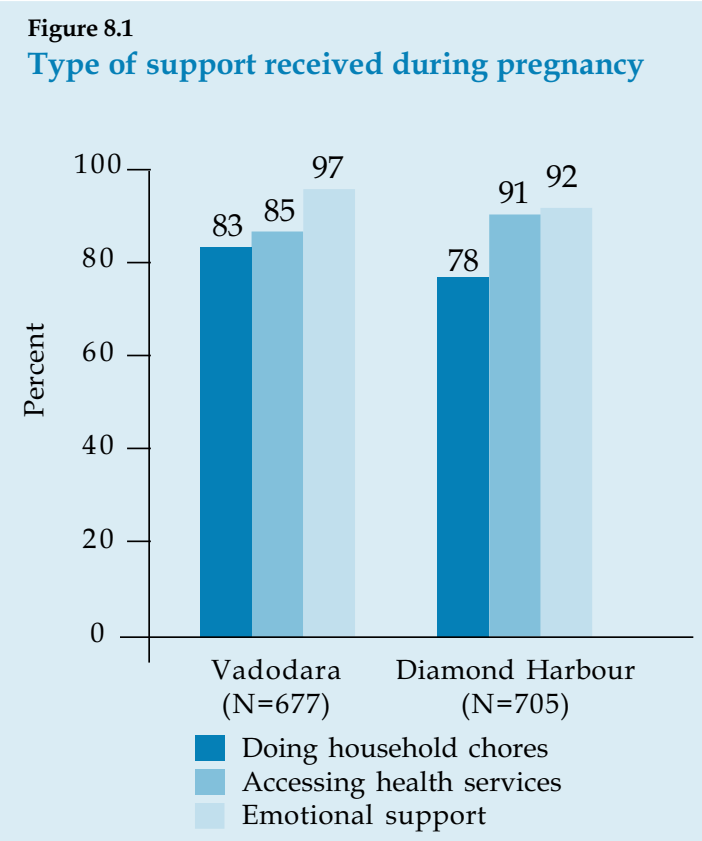

(Figure 8.1). In both sites, women most frequently mentioned mothers-in-law as the person who helped with household chores (72 percent in Vadodara and 63 percent in Diamond Harbour), while husbands were the main person who helped them to access health services (56 percent and 59 percent respectively) and provided emotional support (87 percent and 86 percent respectively).

\section{Harassment during pregnancy}

While an overwhelming majority of pregnant young women reported receiving physical and emotional support during pregnancy, a substantial minority of women in both sites $(8$ percent in Vadodara and 9 percent in Diamond Harbour) also reported being harassed during their pregnancy (Table 8.1). Mothers-in-law, followed by sisters-in-law, were the most commonly mentioned perpetrators in Vadodara, while in Diamond Harbour, mothers-in-law followed by husbands were most often mentioned. The most common form of harassment was forcing the young woman to do all the household chores, preventing her from taking rest or verbally harassing her for not doing the housework. 
Table 8.1

Person who harassed married young women during pregnancy

\begin{tabular}{l|c|c|} 
Person who harassed & $\begin{array}{c}\text { Vadodara } \\
(\%)\end{array}$ & $\begin{array}{c}\text { Diamond Harbour } \\
(\%)\end{array}$ \\
\hline Mother-in-law & 62.0 & 68.9 \\
Sister-in-law & 36.0 & 14.8 \\
Husband & 14.0 & 27.9 \\
Father-in-law & 12.0 & 19.7 \\
Brother-in-law & 6.0 & 3.3 \\
Mother & -- & 1.6 \\
Others & 8.0 & 1.6 \\
\hline N & $\mathbf{5 0}$ & $\mathbf{6 1}$
\end{tabular}

Note: Respondents were asked whether anyone had harassed them or made them 'feel bad' during pregnancy.

\section{Support during delivery}

Receiving some form of support in preparation for delivery is universal in both sites. However, when analysed, there were considerable gaps in specific types of assistance provided (see Figure 8.2). Thus, while the most common forms of support for delivery in both sites--saving money to meet delivery expenses and emotional support- were nearly universal (94 percent and 98 percent respectively in Vadodara and 96 percent and 98 percent respectively in Diamond Harbour), other important forms of support related to delivery

\section{Figure 8.2}

Type of support received during delivery

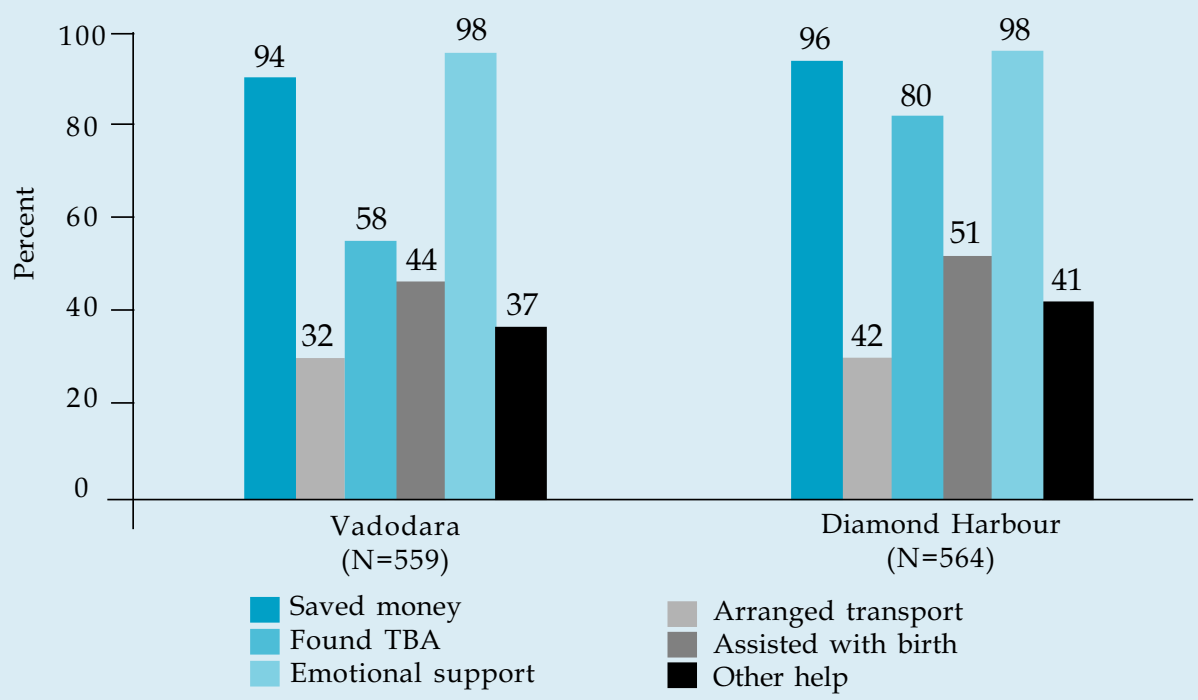


were not as prevalent. For example, the least common form of support that young mothers received was arranging transport to go to a hospital for delivery, with only 32 percent of respondents in Vadodara and 42 percent in Diamond Harbour reporting such assistance. Family members helping to find a traditional birth attendant was more common in Diamond Harbour than in Vadodara.

Findings also indicate that different people provide different forms of assistance/support during labour and delivery. In both sites, the husband was the key person who saved money to meet expenses of delivery, which was the major form of support extended by husbands in both sites (29 percent in Vadodara and 48 percent in Diamond Harbour), though a roughly equal proportion of mothers also helped in this respect in Vadodara. In Diamond Harbour, husbands also assisted in arranging transport; nearly onethird of young mothers received such help. Mothers played a key role in finding a traditional birth attendant or in assisting with their daughter's first birth in both sites, though mothersin-law also played a similar role in Diamond Harbour. Indeed, across both sites, for almost all types of assistance for delivery, the proportion of women receiving support from their mothers was larger than those receiving support from their mothers-in-law. Nearly all women reported receiving advice and emotional support during delivery in both sites. While mothers were the major source of such support in Vadodara (73 percent of women mentioning mothers), both husbands and mothers played an equally important role in providing such support in Diamond Harbour (60 percent citing husbands and 56 percent citing mothers).

\section{Support during the postpartum period}

Nearly all young mothers (91 to 99 percent in both sites) reported having received various types of assistance, including help with household chores and taking care of the baby, advice on self-care and baby care, and emotional support during the postpartum period.

\section{Harassment during the postpartum period}

A smaller proportion of young mothers (1.6 percent in Vadodara and 4.5 percent in Diamond Harbour) reported harassment during the postpartum period than during pregnancy in both sites. In both sites, women who experienced harassment during the postpartum period reported that they were harassed by husbands, mothers-in-law or other marital family members. The nature of harassment experienced was similar to that experienced during pregnancy. A few women also reported being harassed because the newborn was female or because the husband or marital family doubted the paternity of the baby. 


\section{CHAPTER 9}

\section{Summary and conclusion}

In policy, program and research discussions on youth sexual and reproductive health in India, as elsewhere, the needs of married adolescent girls and young women are often overlooked. Yet it is very likely that the sexual and reproductive health issues, the ability to exercise informed choice and hence the needs of married adolescent girls and young women are quite different from those of married adult women (or unmarried adolescent girls and young women). While much is assumed, little is known about the lives of married young women.

Given this scenario, IIPS and the Population Council conducted a community-based study of the situation of married young women in two rural settings in Gujarat and West Bengal. The respondents - 1,079 in Vadodara and 1,036 in Diamond Harbour -- included newly-married young women, first-time pregnant young women and first-time mothers. The study offers valuable insights into the social context of the lives of married young women in rural settings in India. It also provides detailed information about married young women's reproductive health knowledge and practices. Key findings from the study are summarised in this chapter.

\section{Married young women's social isolation and limited autonomy}

Findings clearly indicate that the experience of marriage circumscribes a number of dimensions of young women's lives. In both sites, with marriage, work participation sharply declined particularly in Diamond Harbour (by more than two-thirds in Diamond Harbour and one-third in Vadodara). While more married young women worked in Vadodara compared to Diamond Harbour, of those who worked for wages, most had little control over their income, with over 80 percent in Vadodara and just under half in Diamond Harbour handing over all their earnings to others. Decisions relating to whether or not married young women should work also lay with others, though more women in Diamond Harbour felt that they had a significant say in the decision.

Findings also underscore the profound social vulnerability of married young women in rural settings in India. Our analysis suggests that they were clearly 'junior' partners in household decision-making. Their mobility was limited, and irrespective of whether the destination was within or outside the village, the vast majority could not go unaccompanied. Given such restricted mobility, it is not surprising that these women had limited social networks. Most of their connections beyond their husband and in-laws were still within the family, including the natal family. Not only did married young women have few friends in the marital home, but interaction with them was also limited. Moreover, they had virtually no connection with community organisations, groups or clubs; even fewer were 
beneficiaries of NGO or government programmes. However, a relatively large proportion of married young women were connected to the wider world through the media, primarily the radio (in Diamond Harbour) and television (in Vadodara), though roughly 30 percent did not have regular exposure to any media.

\section{Gender role attitudes and experience of physical abuse}

While a large proportion of married young women in both sites held egalitarian gender role attitudes in a few areas, such as women's freedom to work and husbands sharing the responsibility of household chores, the vast majority, especially in Vadodara, adhered to traditional gender role attitudes on many fundamental issues, including schooling for young boys and girls, a young girl's right to decide whom and when to marry, a wife's subservience to her husband's decision and the husband's role in maternal care. A large proportion of women in both sites (over two-thirds in Vadodara and over four-fifths in Diamond Harbour) justified wife-beating for various reasons. Indeed, between 7 and 12 percent of women reported experiencing physical abuse, perpetrated primarily by their husbands.

\section{The marital experience: Transition, intimacy and sexual initiation}

Adolescent marriage is the norm for girls in India. In both sites, the median age at marriage was 17 years; however, marriage at a young age was relatively more common in Vadodara than in
Diamond Harbour. Most husbands were older than their wives, but the interspousal age difference was comparatively less in Gujarat (the median age difference was 2 years in Vadodara compared to 6 years in Diamond Harbour). The vast majority of marriages were arranged, and most young women had not met their husbands before marriage. Moving into the marital home was a lonely and frightening experience for many, but with time, and fairly quickly, many reported getting used to their new lives.

The nature of the relationship that young couples have differs between the two sites. The proportion of married young women who spent time together with their husbands 'frequently' or 'sometimes' was larger in Diamond Harbour than in Vadodara (67 percent versus 42 percent). At the same time, the proportion of women who reported that they 'rarely' or 'never' spend time together was larger in Diamond Harbour than in Vadodara (19 percent versus 10 percent). In the event of conflict between the young woman and members of the family, women in Vadodara found greater support from their husbands than women in Diamond Harbour. Likewise, a significant proportion of women in both sites, especially in Diamond Harbour, reported that they were afraid of disagreeing with their husbands (38 percent in Vadodara and 68 percent in Diamond Harbour). Interestingly, despite their fear of disagreeing with their husbands, a large proportion of women reported telling their husbands when they disagreed with them (73 percent in Vadodara and 68 percent in Diamond Harbour). 
Sexual initiation is largely consonant with marriage. Only a small minority of women (2.2 percent in Vadodara and none in Diamond Harbour) reported premarital sexual relations. Over 70 percent of married young women in Vadodara and about 90 percent in Diamond Harbour reported that they felt frightened before their first sexual intercourse. When asked about their feelings after their experience of first sexual intercourse, almost one-half of women in Vadodara and one-third in Diamond Harbour reported that they enjoyed it; most other respondents did not like it or found it painful or frightening.

\section{Knowledge of reproductive health}

Findings of the study on married young women's reproductive health knowledge present a mixed picture. Women in both sites, especially in Diamond Harbour, were generally aware of different contraceptive methods and some of the signs of complications that a woman might experience during pregnancy, delivery, the postpartum period and that a newborn might experience. However, in-depth knowledge of many of these subjects was limited in both sites, especially in Vadodara. For example, while the vast majority of women, ranging from between nearly one in two in Vadodara to nearly two in three in Diamond Harbour, were aware of the concept of a fertile period, not more than one in seven in either site could accurately identify when the fertile period actually occurs. In addition, women in both sites lacked awareness about many other reproductive health issues. For example, fewer than one in five women knew what determines the sex of a baby, and only 30 percent of women in Vadodara compared to 59 percent in Diamond Harbour knew that a newborn should be breastfed immediately after birth. Knowledge of sexually transmitted infections and HIV was far more limited; only a minority (16 percent) of women had heard of sexually transmitted infections in both sites, and a little over one in five women in Vadodara and slightly less than one in three women in Diamond Harbour had heard of $\mathrm{HIV} / \mathrm{AIDS}$.

Married young women's access to reproductive health information from health care providers was limited in both sites, especially in Vadodara, and the information provided appeared to be skewed toward prenatal care. Only 9 percent of respondents in Vadodara versus 16 percent in Diamond Harbour reported that had a health worker had spoken with them about delaying their first pregnancy, while 6 percent or less had ever been spoken to regarding sexually transmitted infections or HIV/AIDS.

\section{Reproductive health practices}

Study findings on reproductive health practices of married young women indicate several areas that need attention. Though awareness of contraceptive methods was high, contraceptive use was limited, especially in Vadodara; less than half of respondents (34 percent in Vadodara, 48 percent in Diamond Harbour) had ever used any contraceptive method. A substantial proportion 
of women ( 40 percent or more in both sites) preferred to have their first pregnancy at least two years after marriage. Most reported that their husbands desired the first birth earlier than they themselves did. In terms of actual experience, first pregnancy within the first year of marriage was more common in Diamond Harbour than in Vadodara; one-half of women who were married for 12 or more months in Diamond Harbour, compared to one-third in Vadodara, had their first pregnancy within the first year of marriage. The vast majority of women (over 90 percent in Vadodara and 79 percent in Diamond Harbour) said that they desired a total of one or two children. In both sites, most women preferred to have a 24-year interval between their first and second birth, especially in Diamond Harbour (over fourfifths versus nearly three-fifths in Vadodara).

With regard to maternal and child health practices, findings show that over one-half of postpartum women in Vadodara and three-fifths in Diamond Harbour received at least three antenatal check-ups. The majority of women in both sites, especially in Diamond Harbour, made some arrangements for their delivery. Most first births took place in a health facility, especially in Vadodara (three-fifths versus one-half in Diamond Harbour). A larger proportion of deliveries was attended by trained health professionals or trained traditional birth attendants in Vadodara than in Diamond Harbour (83 percent versus 67 percent). The vast majority of young mothers (85 percent in Vadodara and 89 percent in Diamond Harbour) reported that their babies were immunised.
While the above-noted findings are to some extent encouraging, other aspects of maternityrelated care are not as positive. Routine postpartum check-ups were relatively rare; roughly one-quarter of young mothers in Vadodara and less than 10 percent in Diamond Harbour reported having one. The majority of women in both sites did not immediately breastfeed their babies; a little over one-fourth of mothers in Vadodara and over two-fifths in Diamond Harbour had started breastfeeding their babies immediately after birth. Only 35 percent of young mothers in Vadodara and 53 percent in Diamond Harbour reported feeding colostrum to their babies.

\section{Spousal communication and decision- making on reproductive health matters}

Findings indicate that discussions between young women and their husbands on contraceptive use, timing of first pregnancy and spacing the second birth were relatively common in both sites, especially in Diamond Harbour. In both sites, a substantial proportion of women reported taking decisions on such matters jointly, especially with their husbands.

\section{Support for the first birth}

A large proportion of ever-pregnant women in both sites (over three-quarters) reported having received help with household chores during their pregnancy. Mothers-in-law, followed by sistersin-law, mothers and husbands, were the key persons providing this support. Similarly, a large 
proportion of women (85-91 percent) reported having received help in accessing health services during their pregnancy. Over 90 percent of women reported receiving emotional support during this period, primarily from their husbands (86-87 percent of respondents in both sites mentioned husbands as their source of emotional support). Receiving some form of assistance in preparing for the delivery was nearly universal in both sites. However, when analysed, there were considerable gaps in specific forms of support received. Thus while the most common forms of support for delivery in both sites - saving money for meeting delivery expenses and emotional support-- was high (i.e., roughly 95 percent), other critical delivery-related assistance was not as prevalent. The least common type of support that women received was arranging transport to go to a hospital, with only 32 percent of respondents in Vadodara and 42 percent in Diamond Harbour reporting such assistance. Nearly all women reported having received support during the postpartum period in both sites such as help with household chores and taking care of the baby, advice on self-care and baby care, and emotional support. Support from non-family members was negligible.

While an overwhelming majority of pregnant young women reported receiving physical and emotional support during pregnancy, roughly one in ten reported being harassed or made to 'feel bad' during their pregnancy, mostly by mothersin-law and sisters-in-law. Harassment during the postpartum period was not common (less than 5 percent of respondents reporting harassment).

\section{Conclusion}

Overall, findings indicate an optimistic, but complex and challenging picture of the situation of married young women. Most women are imbedded in a social order that isolates and silences them. Yet, many young brides find support from their husbands, and many come to feel comfortable in their new home and to enjoy intimate sexual relations with their husbands.

The same gatekeepers who isolate also support young married women during their transition to motherhood, providing them healthseeking and emotional support. A priority for programmes would be to build on the positive elements of this social support. At the same time, programmes would need to constructively prevent misinformation and harmful practices, and address the considerable gaps that remain in maternal and child care and the prevention of infection.

It is also clear that existing services are missing critical opportunities to help young couples achieve their reproductive intentions, provide crucial postpartum maternal and neonatal guidance and care, and communicate accurate information on reproduction, contraception and the prevention of infection. Augmenting and redirecting services and outreach to these young women are unlikely to be adequate; it is also critical to directly address and ameliorate their social and economic disadvantage and isolation, as well as engage husbands, mothers and mothers-in-law in programmes for married young women. 


\section{References}

Bruce, J. and S. Clark. 2003. "Including married adolescents in adolescent reproductive health and HIV/AIDS policy," paper presented at the Technical Consultation on Married Adolescents, organised by World Health Organisation, 9- 12 December, Geneva.

Registrar General of India. 2001. Census of India, Provisional Population Totals, Series I, Paper I. 2001. Office of Registrar General. New Delhi: India.

International Institute for Population Sciences (IIPS) and ORC Macro. 2000. National Family Health Survey (NFHS-2) 1998-99: India. Mumbai: International Institute for Population Sciences.

International Institute for Population Sciences (IIPS). 2001. Reproductive and Child Health Project: Rapid Household Survey (Phase 1 and II), 1998-99. Mumbai: International Institute for Population Sciences.

Jejeebhoy, S. 2000. “Adolescent sexual and reproductive behaviour: A review of the evidence from India," in Women's Reproductive Health in India, ed. R. Ramasubban and S. Jejeebhoy. Jaipur: Rawat Publications, pp. 40-101.

Lloyd, C., S. Singh., N. Astone et al. 2005. "The transition to parenthood," in Growing up Global: The Changing Transitions to Adulthood in Developing Countries, ed. C. Lloyd. Washington, D.C.: National Academies Press, pp. 506-571.

Miller, S and F. Lester. 2003. "Improving the health and well-being of married young first time mothers," paper presented at the Technical Consultation on Married Adolescents, organised by World Health Organisation, 9-12 December, Geneva.

Santhya, K.G. and S.J. Jejeebhoy. 2006 "Young women's experiences of forced sex within marriage: Evidence from India," in Sex without Consent: Young People in Developing Countries, ed. S.J. Jejeebhoy, I. Shah and S. Thapa. London: Zed Books, pp. 59-73. 


\section{Appendix 1}

\section{Computation of Standard of Living Index}

A composite index was computed based on type of house, ownership of agricultural land/livestock and ownership of household durables. The score assigned to each individual item was similar to that of National Family Health Survey (NFHS)-2. A detailed description of the variables and the score assigned in computing the standard of living index is given below.

House type: 4 for pucca, 2 for semi-pucca and 0 for kachha

Ownership of agricultural land: 3 for those with 3 or more acres, 2 for those with 1-3 acres, 1 for those with less than 1 acre and 0 for landless

Ownership of livestock: 2 if household owns livestock and 0 if they do not

Pressure cooker: 1 if household owns a pressure cooker and 0 if not

Electric fan: 2 if household owns a fan and 0 if not

Bicycle: 2 if household owns a bicycle and 0 if not

Radio: 2 if household owns a radio and 0 if not

Sewing machine: 2 if households owns a sewing machine and 0 if not

Telephone: 2 if household owns a telephone and 0 if not

Refrigerator: 3 if household owns a refrigerator and 0 if not

Television: 4 if household owns a television and 0 if not

Motorcycle: 3 if household owns a motorcycle and 0 if not

Car/tractor: 4 if household owns a car/tractor and 0 if not.

The composite index was computed by summing up the scores given to each of the items. The value of the index ranged from 0 to 34 . On the basis of distribution, $0-4$ was classified as low, 5-14 as medium and 15 and above as high. 


\section{Authors}

F. Ram is Professor and Head, Department of Fertility Studies, International Institute for Population Sciences, Mumbai

R.K. Sinha is Reader and Head, Department of Extra Mural Studies and Distance Education, International Institute for Population Sciences, Mumbai

S.K. Mohanty is Lecturer, Department of Development Studies, International Institute for Population Sciences, Mumbai

Arup Das is In-charge, Diamond Harbour Unit, Child In Need Institute, Kolkata

Aruna Lakhani is Independent Consultant and formerly, Director, Deepak Charitable Trust, Vadodara

Nicole Haberland is Programme Associate, Population Council, New York

K.G. Santhya is Senior Programme Officer, Population Council, New Delhi 


\section{(P) Population Council}

South \& East Asia-Regional Office Zone 5-A Ground Floor

India Habitat Centre

Lodi Road

New Delhi- 110 003, India

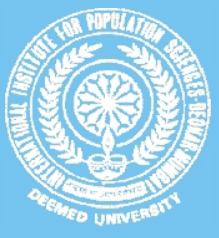

International Institute for Population Sciences Govandi Station Road, Deonar Mumbai - 400 088, India

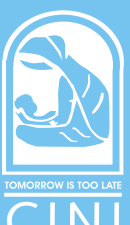

Child In Need Institute

Diamond Harbour Unit

Rayanagar (West), Water Tank Para

Diamond Harbour, 24, Pargnas (South)

West Bengal - 743331 